\title{
Diversity of Phototrophic Genes Suggests Multiple Bacteria May Be Able to Exploit Sunlight in Exposed Soils from the Sør Rondane Mountains, East Antarctica
}

\author{
Guillaume Tahon, Bjorn Tytgat and Anne Willems* \\ Laboratory of Microbiology, Department of Biochemistry and Microbiology, Ghent University, Ghent, Belgium
}

OPEN ACCESS

Edited by:

Hongchen Jiang,

Miami University, USA

Reviewed by:

Wei Lin,

Institute of Geology and Geophysics

(CAS), China

Charles K. Lee,

University of Waikato, New Zealand

${ }^{*}$ Correspondence:

Anne Willems

Anne.Willems@UGent.be

Specialty section:

This article was submitted to

Terrestrial Microbiology,

a section of the journal

Frontiers in Microbiology

Received: 23 September 2016 Accepted: 02 December 2016 Published: 19 December 2016

Citation:

Tahon G, Tytgat B and Willems A (2016) Diversity of Phototrophic Genes Suggests Multiple Bacteria May Be Able to Exploit Sunlight in Exposed Soils from the Sør Rondane

Mountains, East Antarctica.

Front. Microbiol. 7:2026.

doi: 10.3389/fmicb.2016.02026
Microbial life in exposed terrestrial surface layers in continental Antarctica is faced with extreme environmental conditions, including scarcity of organic matter. Bacteria in these exposed settings can therefore be expected to use alternative energy sources such as solar energy, abundant during the austral summer. Using Illumina MiSeq sequencing, we assessed the diversity and abundance of four conserved protein encoding genes involved in different key steps of light-harvesting pathways dependent on (bacterio)chlorophyll (pufM, bchL/ch/L, and bchX genes) and rhodopsins (actinorhodopsin genes), in exposed soils from the Sør Rondane Mountains, East Antarctica. Analysis of pufM genes, encoding a subunit of the type 2 photochemical reaction center found in anoxygenic phototrophic bacteria, revealed a broad diversity, dominated by Roseobacter- and Loktanella-like sequences. The bchL and chlL, involved in (bacterio)chlorophyll synthesis, on the other hand, showed a high relative abundance of either cyanobacterial or green algal trebouxiophyceael chlL reads, depending on the sample, while most bchX sequences belonged mostly to previously unidentified phylotypes. Rhodopsin-containing phototrophic bacteria could not be detected in the samples. Our results, while suggesting that Cyanobacteria and green algae are the main phototrophic groups, show that light-harvesting bacteria are nevertheless very diverse in microbial communities in Antarctic soils.

Keywords: Princess Elisabeth Station, Sør Rondane Mountains, anoxygenic phototrophic bacteria, actinorhodopsin, light-harvesting, AAP

\section{INTRODUCTION}

Antarctica is nearly completely covered by ice, with only $\sim 0.32 \%$ of its surface ice-free. Although most of the ice-free regions are found in the Antarctic Peninsula and the Transantarctic Mountains, inland mountain ranges, such as the Sør Rondane Mountains (Dronning Maud Land), also represent an important fraction of the exposed surface area (Convey et al., 2008; Cary et al., 2010). The absence of vascular plants in continental Antarctica combined with the extreme environmental conditions have led to depleted soils with low availability of nutrients, especially of organic carbon, and nitrogen, and water (Kennedy, 1993; Cary et al., 2010; Tytgat et al., 2016). As a result, the mainly microscopic life in these areas (Cowan et al., 2014; Tytgat et al., 2014; Obbels et al., 2016) may thus 
be expected to use alternative energy sources to overcome these limitations. Sunlight, abundantly available during the austral summer, may be an important resource for certain members of the bacterial communities inhabiting exposed continental environments, and this should be reflected in the diversity of key genes for light-harvesting functions.

As life on Earth evolved, microorganisms developed different ways to harvest solar energy. Two main mechanisms have been described, either using rhodopsins or complex photochemical reaction centers that contain (bacterio)chlorophyll (Bryant and Frigaard, 2006). Early phototrophic prokaryotes $(\sim 3.5$ Giga annum ago) used reductants such as $\mathrm{H}_{2}, \mathrm{Fe}^{2+}$, or $\mathrm{H}_{2} \mathrm{~S}$ for bacteriochlorophyll-dependent anaerobic anoxygenic phototrophy and did not involve oxygen (Hohmann-Marriott and Blankenship, 2011; Butterfield, 2015; Cardona, 2016). Later on (at least $\sim 2.4$ Giga annum ago), oxygenic chlorophylldependent phototrophy, using $\mathrm{H}_{2} \mathrm{O}$, arose in Cyanobacteria and played a key role in oxygenating the Earth's atmosphere (Butterfield, 2015; Cardona, 2016). Under these new atmospheric conditions, many of the anaerobic anoxygenic phototrophic bacteria may have disappeared from the now oxygenated habitats, although some groups adapted and embarked on an aerobic lifestyle (Kobližek, 2015). These aerobic anoxygenic phototrophic bacteria (AAP) were first reported in 1978 (Harashima et al., 1978) and are defined as aerobic species that synthesize bacteriochlorophyll and use light energy as an auxiliary energy source for their mostly heterotrophic metabolism (Feng et al., 2011a; Kobližek, 2015). Moreover, they do not contain carbon fixation enzymes (Yurkov and Csotonyi, 2009). Since their discovery nearly four decades ago, numerous AAP, predominantly belonging to the Proteobacteria, have been described from various habitats (Kobližek, 2015). Some species capable of aerobic anoxygenic phototrophy have also been found in the Gemmatimonadetes, Acidobacteria, and Chloroflexi. Phototrophic species belonging to the latter phylum are, however, not included in the AAP, as are many other aerobic bacteria that synthesize Bchl and perform anoxygenic phototrophy under aerobic conditions (e.g., phototrophic methylotrophs, Yurkov and Csotonyi, 2009; Zeng et al., 2014; Kobližek, 2015). The majority of all aforementioned anoxygenic phototrophs rely on a heterodimeric type 2 reaction center with pufL and $p u f M$ encoding the conserved proteins. Hence, these two puf genes are frequently used and convenient markers to study the diversity of anoxygenic phototrophic bacteria (Koh et al., 2011; Ritchie and Johnson, 2012; Kobližek, 2015).

Additionally, several other genes encoding subunits of key enzymes in the (bacterio)chlorophyll synthesis pathway are also well conserved among phototrophic microorganisms. All oxygenic and anoxygenic phototrophic bacteria use the darkoperative protochlorophyllide oxidoreductase (DPOR) enzyme complex, encoded by the chlLNB and $b c h L N B$ genes, respectively.

\footnotetext{
Abbreviations: AAP, aerobic anoxygenic phototrophic bacteria; APB, anoxygenic phototrophic bacteria; COR, chlorin oxidoreductase; DPOR, dark-operative protochlorophyllide oxidoreductase; ML, maximum likelihood; OLU, operational ChlL/BchL unit; OPU, operational puf unit; OXU, operational BchX unit.
}

Apart from in bacteria, DPOR is also found in green algae and lower land plants (Nomata et al., 2014). The complex plays a key role in the biosynthesis of (bacterio)chlorophyll, converting protochlorophyllide to chlorin (Fujita and Bauer, 2003; Gupta, 2012). Whereas, in Cyanobacteria, green algae and lower land plants, chlorin is converted immediately to chlorophyll $(\mathrm{Chl})$, in anoxygenic phototrophic bacteria (APB) a second enzyme complex, chlorin oxidoreductase (COR), encoded by $b c h X Y Z$ genes, reduces chlorin to bacteriochlorophyllide, the direct precursor for bacteriochlorophyll (Bchl) (Beale, 1999; Chew and Bryant, 2007). DPOR and COR exhibit a high degree of structural similarity. Interestingly, the amino acid sequences of the different DPOR and COR subunits (BchLNB/ChlLNB and BchXYZ, respectively), exhibit significant similarity $(\sim 15-30 \%)$ to those of the nitrogenase enzyme complex (NifHDK), leading to the hypothesis that these three enzyme complexes all evolved from the same common ancestor (Fujita and Bauer, 2003; Reinbothe et al., 2010; Gupta, 2012).

Besides phototrophy using photochemical reaction centers, a second type of phototrophy, employing rhodopsins also evolved (Bryant and Frigaard, 2006), although little is known about its origin in time. Microbial rhodopsins have been described in various groups, mostly in aquatic habitats, performing a range of functions, including light-driven ion pumping (Béjà and Lanyi, 2014; Boeuf et al., 2015). Although previously detected in Siberian permafrost (Petrovskaya et al., 2010), Antarctic sea ice, sea water, and continental lakes (Béjà et al., 2001; Koh et al., 2010; Qin et al., 2012; Williams et al., 2012; Yau et al., 2013; Do et al., 2014; Markowitz et al., 2014), little rhodopsin data are available for terrestrial Antarctica (based on metagenome data available on MG-RAST Wilke et al., 2016 and IMG Markowitz et al., 2014). Recently, a new family of proton pumping microbial rhodopsins, actinorhodopsins, has been discovered in freshwater Actinobacteria, (Sharma et al., 2008). To our knowledge, their occurrence in Antarctica has not been reported yet.

A first cloning survey of genes for phototrophic mechanisms in samples from the oligotrophic high-altitude soils near the Belgian Princess Elisabeth Station in the Sør Rondane Mountains revealed a high diversity of pufLM genes, whereas proteorhodopsin genes could not be amplified from any of the samples (Tahon et al., 2016). In this study, we aimed to more comprehensively assess the diversity of bacteria capable of exploiting sunlight as an alternative energy source. To further test the hypothesis that sunlight may be a very important resource for certain members of the bacterial communities inhabiting these exposed oligotrophic soils, an Illumina MiSeq paired-end $300 \mathrm{bp}$ sequencing approach was used with primers targeting pufM, actinorhodopsin and $b c h L / \operatorname{chl} l / b c h X$ genes. For the latter, sequence data obtained in a previous study into the diversity of nifH genes (Tahon et al., under review), that were originally discarded because they lacked multiple of the conserved NifH amino acid residues, were revisited. Further analyses reported here identified these sequences as the NifH homologs BchL/ChlL and BchX, involved in the (bacterio)chlorophyll synthesis pathways (Fujita and Bauer, 2003; Raymond et al., 2004). 


\section{MATERIALS AND METHODS}

\section{Study Site and Sample Collection}

Four samples, previously used in the pilot survey (Tahon et al., 2016), were studied (Table 1), to allow comparison. During the Antarctic summer of 2009, top surface samples-mostly consisting of weathered granite parent material-were collected aseptically in the vicinity of the Belgian Princess Elisabeth Station $\left(71^{\circ} 57^{\prime} \mathrm{S}, 23^{\circ} 20^{\prime} \mathrm{E}\right)$ at Utsteinen, Dronning Maud Land, East Antarctica. All samples were frozen at $-20^{\circ} \mathrm{C}$ upon collection. Sample KP2 was collected $\sim 1.3 \mathrm{~km}$ south of the research station. The three other samples were collected on the Utsteinen ridge, $\sim 500 \mathrm{~m}$ north of the Belgian base.

\section{DNA Extraction}

From each homogenized sample, $400 \mathrm{mg}$ subsamples were taken in triplicate. Total genomic DNA was extracted and purified using the PowerLyzer ${ }^{\circledR}$ PowerSoil ${ }^{\circledR}$ DNA isolation kit (MoBio Laboratories) and a modified lysis protocol as instructed by the manufacturer. This extraction protocol was previously identified as the one yielding most bacterial diversity (Tahon et al., 2016). Following extraction, DNA was quantified using the Qubit ${ }^{\circledR}$ 2.0 fluorometer (Life Technologies) and stored at $-20^{\circ} \mathrm{C}$ until processing.

\section{PCR and Preparation for Illumina Sequencing}

A Veriti thermal cycler (Life Technologies) was used to amplify partial actinorhodopsin, pufM, bchL/chlL, and $b c h X$ genes. Primer selection was based on two criteria: (1) to amplify a broad diversity of the gene and (2) to produce an amplicon size suitable for Illumina MiSeq 300 bp paired-end sequencing (Table 2). To complement the Nextera XT index kit (Illumina), primers were extended with an adapter.

For each of the soil samples, PCR was performed in triplicate on all three DNA extracts, for each primer set, resulting in a total of nine PCR products per sample per gene. PCRs were performed in $25 \mu \mathrm{l}$ reaction mixtures containing $3 \mu \mathrm{l}$ of genomic DNA (>6 ng $\mu \mathrm{l}^{-1}$ ), 1x Qiagen PCR buffer (Qiagen), $0.2 \mathrm{mM}$ of each deoxynucleotide triphosphate, $0.625 \mathrm{U}$ of Qiagen Taq polymerase (Qiagen), $100 \mathrm{mM}$ bovine serum albumin and forward and reverse primer with final concentrations as shown in Table 2. All nine PCR products (three DNA extracts $x$ three PCRs) were pooled and purified using the Ampure beads XT (Agencourt) protocol with slight modifications. Briefly, only 0.8 reaction volume of beads was used and DNA was resuspended in MilliQ water. Tagging of pooled PCR products was performed using the Nextera XT indices (Illumina) during an eight cycle version of the amplicon PCR with the indices replacing the primers. Afterwards, PCR products were purified as described above, with resuspension in Tris buffer $(0.1 \mathrm{M}, \mathrm{pH}$ 8.5). Integrity and amplicon sizes of the PCR products were checked using a BioAnalyzer (Agilent), following quantification using a Qubit, as described above. Afterwards, samples were pooled equimolarly and sequenced on an Illumina MiSeq 300 bp paired-end platform (GATC). PhiX was spiked at $20 \%$ per lane.

\section{Sequence Data Processing}

For all genes, the forward and reverse sequencing reads were merged using the fastq_mergepairs command in USEARCH (Edgar, 2010) allowing a minimum overlap length of 8 nucleotides and a maximum of six mismatches in the overlapping region. For $b c h L / \operatorname{chlL} / b c h X$, and $p u f M$, merged sequences shorter than 370 and 200, and longer than 470 and 350, were removed using the fastq_minmergelen and fastq_maxmergelen commands, respectively. Primer sequences were removed from the merged sequences using cutadapt v1.8 (Martin, 2011), resulting in sequences with a minimum length of 193 and $321 \mathrm{bp}$, and a maximum length of 225 and 369 bp for pufM and $b c h L / c h l L / b c h X$, respectively. Subsequently, during quality filtering using USEARCH, sequences with one or more nucleotides beneath the Phred Q20 threshold score and a maximum error $>0.5$ were removed from further analyses. Afterwards, all sequences were placed in reading frame +1 , followed by removal of sequences showing no similarity to our genes of interest or containing stop codons and/or indels resulting in a frameshift. Detection of putative chimeric sequences was done using the Uchime model (default parameters, Edgar et al., 2011) in Mothur (Schloss et al., 2009). Finally, all remaining sequences were translated to proteins using MEGA 6 using the bacterial genetic code (Tamura et al., 2013).

\section{Sequence Analyses}

For pufM, an updated version of our previously described database containing publicly available sequences (Tahon et al., 2016) was used. For $b c h L / c h l L$ and $b c h X$ a new database was assembled to contain all related sequence records from NCBI and IMG (https://img.jgi.doe.gov/) (Markowitz et al., 2012) available per November 15th 2015. Newly obtained nucleotide sequences and their derived protein sequences were added to

TABLE 1 | Parameters associated with analyzed samples.

\begin{tabular}{|c|c|c|c|c|c|c|c|}
\hline Sample & Sample coordinates & $\begin{array}{l}\text { Altitude } \\
\text { (m) }\end{array}$ & Description of sample area & $\begin{array}{l}\text { Conductivity } \\
(\mu \mathrm{S} / \mathrm{cm})\end{array}$ & $\mathrm{pH}$ & $\begin{array}{l}\text { Water } \\
\text { content }\end{array}$ & TOC \\
\hline KP2 & $71^{\circ} 57^{\prime} 28.6^{\prime \prime} \mathrm{S}, 23^{\circ} 19^{\prime} 45.8^{\prime \prime} \mathrm{E}$ & 1320 & $\begin{array}{l}\text { Small gravel particles in between rocks, Utsteinen } \\
\text { nunatak }\end{array}$ & 19 & 6.54 & $6.28 \%$ & $0.08 \%$ \\
\hline KP15 & $71^{\circ} 56^{\prime} 45.8^{\prime \prime} \mathrm{S}, 23^{\circ} 20^{\prime} 43.6^{\prime \prime} \mathrm{E}$ & 1366 & Brown soil under lichen, East part of Utsteinen ridge & 33 & 5.57 & $3.38 \%$ & $0.33 \%$ \\
\hline KP43 & $71^{\circ} 56^{\prime} 47.3^{\prime \prime} \mathrm{S}, 23^{\circ} 20^{\prime} 44.6^{\prime \prime} \mathrm{E}$ & 1362 & $\begin{array}{l}\text { Brown soil with dark green fragments, East part of } \\
\text { Utsteinen ridge }\end{array}$ & 520 & 6.22 & $0.91 \%$ & $2.57 \%$ \\
\hline KP53 & $71^{\circ} 56^{\prime} 45.3^{\prime \prime} \mathrm{S}, 23^{\circ} 20^{\prime} 42.4^{\prime \prime} \mathrm{E}$ & 1362 & Grey soil on East part of Utsteinen ridge & 312 & 6.34 & $0.23 \%$ & $0.21 \%$ \\
\hline
\end{tabular}


TABLE 2 | PCR primers (without adapters) and conditions used for screening different genes.

\begin{tabular}{|c|c|c|c|c|c|c|c|}
\hline Gene & Target & Primer & Sequence $5^{\prime}-3^{\prime}$ & $\begin{array}{l}\text { Final } \\
\text { concentration }\end{array}$ & Region & $\begin{array}{l}\text { Amplicon } \\
\text { size }\end{array}$ & Program 9 \\
\hline \multirow[t]{2}{*}{ pufM } & Universal & pufM_uniFa & $\begin{array}{l}\text { GGN AAY YTN TWY TAY } \\
\text { AAY CCN TTY CA }\end{array}$ & $1.0 \mu \mathrm{M}$ & $584-825^{d}$ & $\pm 240 \mathrm{bp}$ & $\begin{array}{l}94^{\circ} \mathrm{C}(4 \mathrm{~min}) ; 35 \times 94^{\circ} \mathrm{C}(40 \mathrm{~s}) \\
49^{\circ} \mathrm{C}(30 \mathrm{~s}), 72^{\circ} \mathrm{C}(30 \mathrm{~s}) ; 72^{\circ} \mathrm{C} \\
(7 \mathrm{~min})\end{array}$ \\
\hline & & pufM_WAWa & $\begin{array}{l}\text { AYN GCR AAC CAC CAN } \\
\text { GCC CA }\end{array}$ & $0.5 \mu \mathrm{M}$ & & & \\
\hline \multirow[t]{4}{*}{ actinorhodopsin } & $\begin{array}{l}\text { Clade LG1 \& } \\
\text { LG2 }\end{array}$ & LG-forb & $\begin{array}{l}\text { TAY MGN TAY GTN GAY } \\
\text { TGG }\end{array}$ & $0.4 \mu \mathrm{M}$ & $283-614^{e}$ & $\pm 330 \mathrm{bp}$ & $\begin{array}{l}95^{\circ} \mathrm{C}(7 \mathrm{~min}), 45 \times 94^{\circ} \mathrm{C}(30 \mathrm{~s}) \\
51.5^{\circ} \mathrm{C}(1 \mathrm{~min} 30 \mathrm{~s}), 72^{\circ} \mathrm{C}(30 \mathrm{~s}) \\
72^{\circ} \mathrm{C}(10 \mathrm{~min})\end{array}$ \\
\hline & & LG1A-forb & MGN TAY ATH GAY TGG YT & $0.4 \mu \mathrm{M}$ & & & \\
\hline & & LG2-forb & $\begin{array}{l}\text { TAY MGN TAY GCN GAY } \\
\text { TGG }\end{array}$ & $0.4 \mu \mathrm{M}$ & & & \\
\hline & & LG-rev b & ATN GGR TAN CAN CCC CA & $0.8 \mu \mathrm{M}$ & & & \\
\hline \multirow[t]{2}{*}{$\begin{array}{l}\text { nifH, bchL, } \\
\text { chll, bchX }\end{array}$} & Universal & $\mathrm{IGK}^{\mathrm{C}}$ & $\begin{array}{l}\text { GCl WTH TAY GGI AAR GGI } \\
\text { GGI ATH GGI AA }\end{array}$ & $1.0 \mu \mathrm{M}$ & $19-413^{f}$ & 395 bp & $\begin{array}{l}95^{\circ} \mathrm{C}(10 \mathrm{~min}) ; 40 \times 95^{\circ} \mathrm{C}(45 \mathrm{~s}) \\
52^{\circ} \mathrm{C}(30 \mathrm{~s}), 72^{\circ} \mathrm{C}(40 \mathrm{~s}) ; 72^{\circ} \mathrm{C} \\
(10 \mathrm{~min})\end{array}$ \\
\hline & & $\mathrm{DW}^{\mathrm{C}}$ & $\begin{array}{l}\text { ATI GCR AAI CCI CCR CAI } \\
\text { ACI ACR TC }\end{array}$ & $1.0 \mu \mathrm{M}$ & & & \\
\hline
\end{tabular}

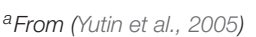

${ }^{b}$ From (Sharma et al., 2009)

${ }^{c}$ From (Ando et al., 2005)

${ }^{d}$ Based on the pufM sequence of Sphingomonas sanxanigenens DSM 19645 (CP006644)

${ }^{e}$ Based on the actinorhodopsin sequence of Leifsonia rubra CMS 76R (ATIA01000023)

${ }^{f}$ Based on the nifH sequence of Azotobacter vinelandii (M20568)

${ }^{g}$ All programs were optimized in this study.

the databases using the import module of BioNumercs 7.5 (Applied Maths). For the sequences obtained with the primer set IGK3/DVV, to retain only BchL/ChlL (L subunit of DPOR) and $\mathrm{BchX}$ (X subunit of $\mathrm{COR}$ ) sequences, NifH sequences were separated based on the presence of the conserved amino acid residues Ala43, the dipeptide Glu93-Pro94, Arg101, the dipeptide Ile104-Thr105 and Glu111 (positions based on the NifH protein sequence of Azotobacter vinelandii, accession number M20568, Fujita and Bauer, 2003). For phylogenetic analyses, all Illumina PufM sequences were clustered at a 95\% cut-off using CDHIT (Li and Godzik, 2006; Fu et al., 2012), grouping them into operational puf units (OPUs) of which one representative was used to construct the phylogenetic tree. BchL/ChlL and BchX sequences were grouped in operational BchL/ChlL units (OLUs) and operational BchX units (OXUs), respectively, at 95\% cutoff. BchL/ChlL and BchX sequences were processed together for phylogenetic analyses. A first alignment was made with all sequences present in our databases, using Clustal Omega (Goujon et al., 2010; Sievers et al., 2011). Afterwards, alignments were trimmed to the size of our sequenced amplicons and visually inspected, excluding from further analysis all nonoverlapping reference sequences. Remaining sequences were realigned, after which the alignment was used to construct a maximum likelihood (ML) phylogenetic tree (1000 bootstrap replicates), by using the FastTree tree building software (Price et al., 2010) with the Whelan and Goldman evolutionary model and the discrete gamma model with 20 rate categories. From the resulting phylogenetic trees, closest relatives of our newly obtained sequences as well as representative sequences from the entire tree were selected to prepare a smaller tree representing the initial complete tree, following the same protocol. Sequences from uncultured bacteria were not included in the final tree. Trees were visualized using the iTOL software (Letunic and Bork, 2007, 2011) and related OPUs, OLUs, or OXUs were grouped into visual clusters that were named after cultivated bacteria that grouped in or close to the cluster. In the absence of cultivated members, the clusters were given an Utsteinen (UT) cluster number designation.

\section{Statistical Analyses}

For statistical analyses of PufM, BchL/ChlL, and BchX sequences, the Vegan package (Dixon, 2003) in $\mathrm{R}$ (https://cran.r-project.org/) was used. A non-normalized table of the total number of protein sequences per OPU, OLU, or OXU was used to perform rarefaction analyses and determine the total number of expected OPUs/OLUs/OXUs per sample and for the four samples combined. Parameters calculated for each dataset include species richness (Chaol) and evenness (Pielou). A normalized table (consensus of 10,000 iterations) of the total number of protein sequences per OPU, OLU, or OXU was also generated, to assess the impact on relative abundances.

\section{Accession Numbers}

Raw sequences were submitted to the NCBI sequence read archive under accession number SRP067116. 


\section{RESULTS}

Actinorhodopsin genes could not be amplified from the samples and were therefore not included in the Illumina run. Sequencing and thorough quality control of sequence data resulted in 678940 high-quality pufM sequences (length 193-198 bp) and 119822 and 4950 high-quality $b c h L / c h l L$ and $b c h X$ sequences (length 321-348 bp). At a 95\% cut-off, the PufM protein sequences constituted 925 OPUs of which 248 were singletons. For BchL/ChlL and BchX, the sequences grouped in 207 OLUs and 48 OXUs, respectively. A total of 48 OLUs and 18 OXUs were singletons (Table 3).

When analyzing sequencing data, there is no consensus on inclusion or removal of singletons. Although many authors choose to remove them, particularly when the focus is on dominant community members (Pedrós-Alió, 2012), we have opted not to do so, for several reasons. Previous research has shown that singletons may be informative and valuable in reflecting rare and/or unique lineages of dormant or inactive bacteria that may grow when the right conditions are met (Logares et al., 2014). Removal of singletons would thus lead to a loss of power to detect these rare lineages in communities and lead to an underestimation of biodiversity levels (Kauserud et al., 2012; Zhan et al., 2013, 2014; Pascual et al., 2016). On the other hand, singletons may represent erroneous sequences and therefore the use of a very stringent quality control is required to accurately sort informative low-abundance sequence reads from errors and artifacts. We therefore implemented a very stringent quality control. The length of the pufM, bchX, and $b c h L / c h l L$ amplicons (Table 2) allowed a large or even complete overlap between the forward and reverse sequencing reads. In the overlapping region, only six mismatches were allowed and every sequence with one or more nucleotides with a base call accuracy lower than 99\% was discarded. Furthermore, since we studied protein-encoding genes rather than $16 \mathrm{~S}$ rRNA genes, a number of additional quality control steps could be performed. The gene sequences were placed in frame +1 , translated into amino acids and these were analyzed for the presence of stop codons, indels that result in a frameshift and presence of conserved sites. These steps allowed additional removal of erroneous sequences so that the number of singleton sequences was reduced a thousand fold and the final data are of much higher quality and likely represent real, though perhaps rare, diversity. Indeed, the vast majority of leftover singletons were found to group within the named clusters or close to sequences of named species (Figures 3, 4A,B, and Table 3, Table S1). As the goal of our study was to explore the (nearly) whole diversity of several protein encoding genes, including rare types, the number of singletons retrieved also aids to get more insight in the diversity coverage of the approach used. To estimate total diversity in a sample different parameters (e.g., Chao1, ACE) can be used (Gotelli and Colwell, 2010, Table 3). Calculation of these parameters takes the number of singletons into account and removal of singletons would confound the ability to estimate alpha diversity.

TABLE 3 | Overview of sequence data characteristics.

\begin{tabular}{|c|c|c|c|c|c|c|c|c|c|c|c|}
\hline & & \multicolumn{5}{|c|}{ Illumina data } & \multicolumn{5}{|c|}{ Normalized data } \\
\hline & No. of OPUs & 509 & 644 & 502 & 463 & 925 & 72 & 85 & 110 & 71 & 171 \\
\hline & No. of singleton OPUs & 44 & 97 & 76 & 31 & 248 & 6 & 18 & 35 & 15 & 74 \\
\hline & No. of identified singleton OPUs ${ }^{a}$ & 43 & 92 & 76 & 31 & 242 & 6 & 16 & 35 & 15 & 72 \\
\hline & Chao1 & 666.51 & 884.32 & 781.40 & 634.92 & 1227.39 & 110.75 & 214.00 & 157.83 & 166.14 & 329.88 \\
\hline \multirow[t]{4}{*}{ BchL/ChIL } & No. of sequences & 72910 & 18836 & 11715 & 16361 & 119822 & 11715 & 11715 & 11715 & 11715 & 46860 \\
\hline & No. of OLUs & 115 & 113 & 75 & 66 & 207 & 82 & 113 & 75 & 66 & 192 \\
\hline & No. of singleton OLUs & 11 & 13 & 17 & 7 & 48 & 7 & 22 & 17 & 9 & 55 \\
\hline & No. of identified singleton OLUs ${ }^{a}$ & 11 & 13 & 16 & 7 & 47 & 7 & 22 & 16 & 9 & 54 \\
\hline \multirow{5}{*}{$B \operatorname{ch} X$} & No. of OXUs & 7 & 19 & 32 & 8 & 46 & & & & & \\
\hline & No. of singleton OXUs & 3 & 5 & 10 & 0 & 18 & & & & & \\
\hline & No. of identified singleton OXUs ${ }^{\mathrm{a}}$ & 3 & 5 & 10 & 0 & 18 & & & & & \\
\hline & evenness $\left(H / H_{\max }\right)$ & 0.623 & 0.315 & 0.168 & 0.216 & 0.231 & & & & & \\
\hline & Chao1 & 13.00 & 30.25 & 45.75 & 8.33 & 67.86 & & & & & \\
\hline
\end{tabular}

Diversity indices were calculated on the basis of derived protein sequences, binned at $95 \%$ similarity.

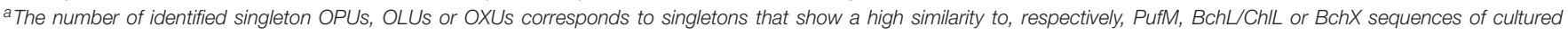
organisms or that belong to the Utsteinen (UT) clusters (details provided in Table S1). 


\section{PufM}

Relative number of Reads per sample

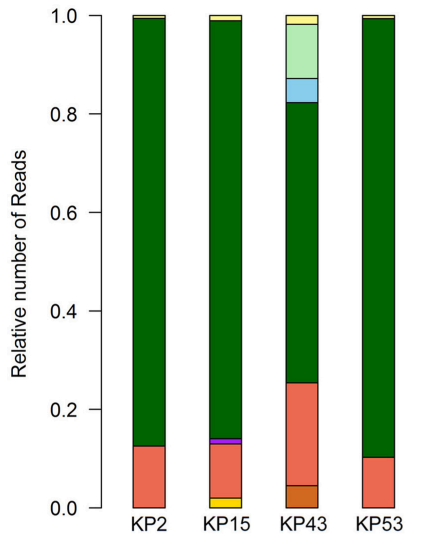

Relative number of OPUs per sample

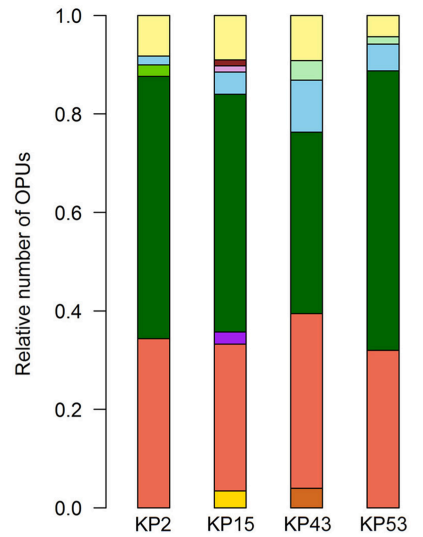

$$
\square<1 \%
$$

$\square$ PUfM UT 5

- PufM UT 3

$\square$ Sphingomonadales-like

$\square$ Skermanella-like

$\square$ Salinarimonas rosea-like

$\square$ Roseobacter-like

Roseiflexus castenholzii-like

$\square$ Loktanella-like

$\square$ Haliea rubra-like

$\square$ Bradyrhizobium sp. S23321-like

\section{BchL/ChIL}

Relative number of Reads per sample

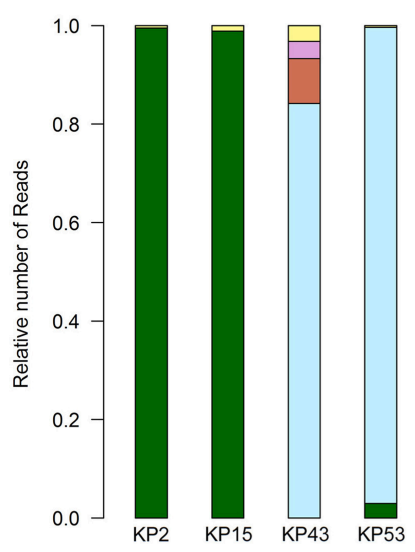

Relative number of OLUs per sample

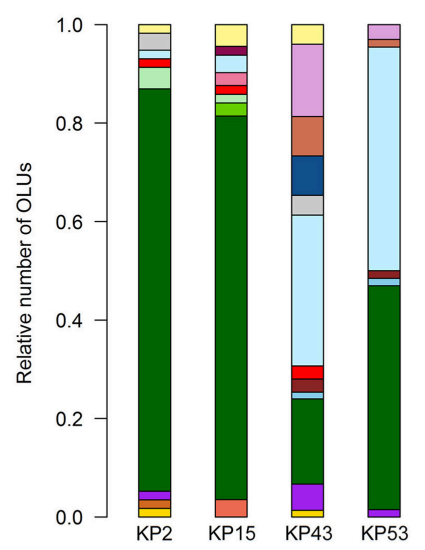

Relative number of Reads per sample
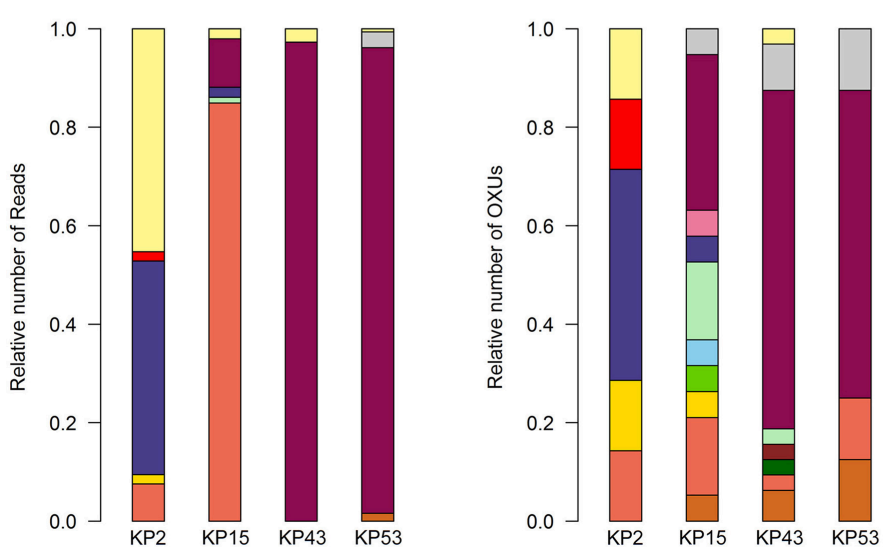

\section{BchX}

Relative number of OXUs per sample

$$
\begin{array}{ll}
\square & <1 \% \\
\square & \text { BchL UT 5 } \\
\square & \text { BchL UT 4 } \\
\square & \text { BchL UT 3 } \\
\square & \text { BchL UT 2 } \\
\square & \text { BchL UT 1 } \\
\square & \text { Trebouxiophyceae-like } \\
\square & \text { Sphingomonas-like } \\
\square & \text { Sphingomonadales-like } \\
\square & \text { Phormidesmis priestleyi Ana-like } \\
\square & \text { Methylobacterium-like } \\
\square & \text { Mesorhizobium-like } \\
\square & \text { Kouleothrix aurantiaca-like } \\
\square & \text { Cyanobacteria-like } \\
\square & \text { Burkholderiales-like } \\
\square & \text { Bradyrhizobium sp. S23321-like } \\
\square & \text { Belnapia-like } \\
\square & \text { Aquincola tertiaricarbonis-like }
\end{array}
$$

FIGURE 1 | Bar plots showing relative numbers of reads and OPUs (PufM), OLUs (BchL/ChIL) or OXUs (BchX) per cluster. Data were not normalized (normalized bar plots are shown in Figure S2). Clusters or separate OPUs/OLUs/OXUs containing less than $1 \%$ of the data were grouped together in the $<1 \%$ group. 
As there is no consensus on the use of normalization which may lead to the omission of valuable diversity data (McMurdie and Holmes, 2014), we assessed how much diversity would be lost by normalizing. For each gene, the original OTU table was normalized 10,000 times. Based on these results, box plots were generated showing the large variation in the OTU diversity recovered after standardization (Figure S1). Therefore, we created a consensus OTU table out of 10,000 standardizations and used this for calculating the relative abundances of reads and OTUs (Figure S2). Surprisingly, differences with relative abundances calculated using non-normalized data (Figure 1) are limited $(<0.05 \%$ for most of the OTUs and clusters). Normalization does, however, involve removal of sequence data and as a result leads to the discarding of (rare) diversity. This is most clear in the BchX dataset where the effect of normalization on sample KP43 is more pronounced as this sample had a very large number of reads and rare OTUs, many of which were removed. To avoid potential loss of rare sequence types, non-normalized data was used in the diversity assessments.

For PufM, of the 925 OPUs, 358 were detected in one sample only (Figure S3, Table S1). The number of OPUs in each sample varied from 463 to 644 (Table 3). Of 228 shared OPUs, two contained the majority of PufM sequences and both grouped with PufM of heterotrophic alphaproteobacterial AAPs. OPU C1 contained $80.11 \%$ of all sequences and was $98.48 \%$ similar to the PufM sequence of Roseobacter denitrificans OCh 114 (Figure 1, Table S1). OPU C2 comprised $12.03 \%$ of all reads and had the PufM sequence of Loktanella sp. RCC2403 as closest match (96.97\% amino acid similarity) (Figure 1, Table S1). Rarefaction analysis showed that, although the graphs started to flatten, saturation was not yet reached (Figure 2). This was corroborated by the number of estimated OPUs (Chao1) that was much higher than the number of observed OPUs (Table 3).

After ML analysis, nearly all 925 OPUs grouped into 28 clusters (Figure 3), mostly containing reads from all four terrestrial samples as well as PufM sequences originating from cultured bacteria (Table 4). The Loktanella-like and Roseobacterlike clusters were the largest, containing 273 and 386 of the OPUs and, since they contained OPUs C2 and C1, they also contained most of the reads: 12.70 and $82.39 \%$ respectively. It should be noted that the cluster defined as Roseobacterlike also contains some PufM sequences of Tateyamaria, Erythrobacter, and Jannaschia ( $<0.1 \%$ of reads). The third largest cluster (PufM UT 5) grouped among less related alphaproteobacterial AAP PufM sequences and contained only $1.59 \%$ of the sequence data, mostly originating from sample KP43 (Figures 1, 3, Table 4). The other clusters and the separate OPUs each contained less than $0.85 \%$ of the reads. In the phylogenetic ML tree, our OPUs grouped with a broad variety of known PufM sequences originating from Alpha-, Beta-, and Gammaproteobacteria, and even Chloroflexi (Figure 3). Affiliations with alphaproteobacterial AAP PufM sequences, however, were most frequent. Several clusters (PufM UT 1-PufM UT 5) and separate OPUs did not group closely with known diversity, suggesting that many organisms harboring $p u f M$ genes still remain unreported.

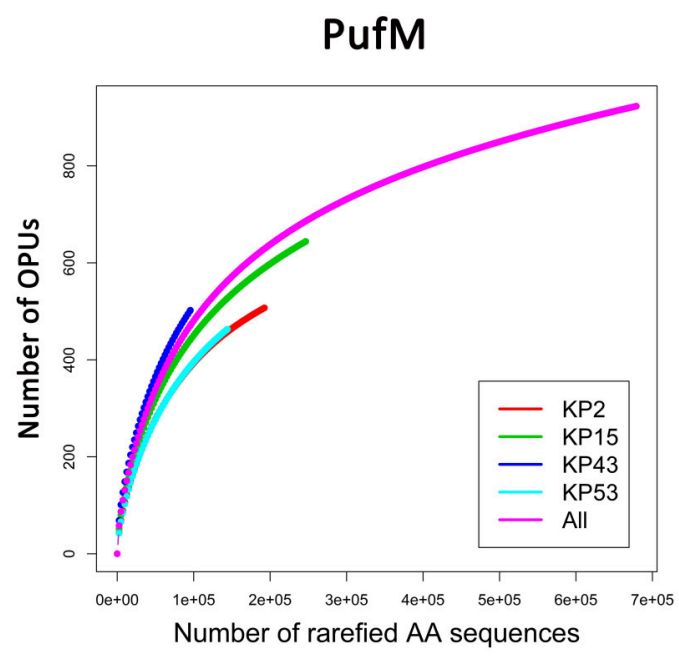

BchL/ChIL

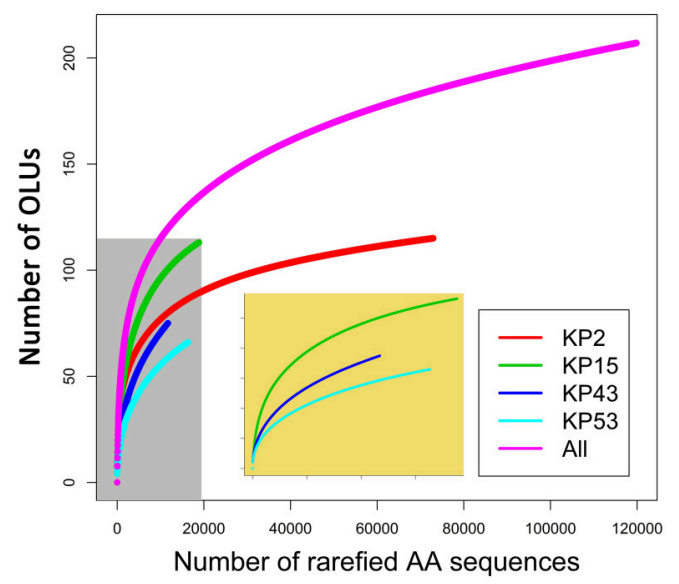

BchX

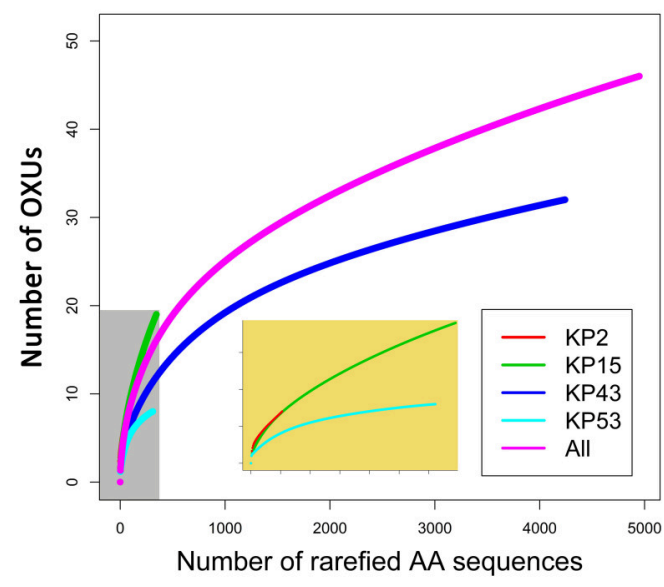

FIGURE 2 | Rarefaction curves based on grouping protein sequences that have $95 \%$ similarity. Analysis was performed using the Vegan package in R. Embedded figures (beige background in BchL/ChlL and BchX) show a more detailed view of rarefaction curves completely enclosed in the gray area. 
The PufM sequences appeared to be cosmopolitan: a broad diversity of cultured and uncultured sequences originating from habitats from all over the world, including polar regions, was found grouping with the new PufM sequences (Table S2). Some clusters, however, represented new PufM phylotypes, as no cultured or environmental PufM sequence was found grouping with them (e.g., cluster PufM UT 3).

The 119822 sequences that grouped with BchL/ChlL reference sequences constituted 207 OLUs, with the number of OLUs per sample varying from 66 to 114 (Table 3). A total of 48 OLUs contained only one sequence, whereas 96 OLUs were restricted to sequences from one sample (Figure S3, Table S1). Nine OLUs were common to all four samples (Figure S3). Of these, three OLUs $(\mathrm{C} 0, \mathrm{C} 1$, and $\mathrm{C} 13)$ together represented $79.07 \%$ of all BchL/ChlL sequences (Table S1). OLU C13 (47.37\% of sequences, mostly from KP2) and OLU C1 (13.38\% of sequences, mostly from KP15) were $\sim 97.7 \%$ similar to the ChlL sequences of Synechococcus sp. PCC 6312 (order Chroococcales, Cyanobacteria) and Microcoleus vaginatus (order Oscillatoriales, Cyanobacteria), respectively (Figure 1). Interestingly, OLU C0, containing $18.33 \%$ of the sequences and retrieved mostly from samples KP43 and KP53, displayed a very high similarity ( 99.1\%) to Trebouxiophyceae ChlL (Figure 1 and Figure S4, Table S1). All remaining OLUs contained less than $3.07 \%$ of the sequences.

Rarefaction analysis (Figure 2) showed saturation was not yet reached for the single, or the pooled samples, although the graphs started to flatten. Indeed, the estimated number of OLUs (Chao1 values) was only slightly higher than the number of observed OLUs, indicating most diversity was retrieved from the samples (Table 3). Furthermore, all samples showed a similar, very uneven distribution (Table 3 ).

After ML analysis, the 207 OLUs could be grouped into 17 clusters, 12 of which grouped with BchL/ChlL sequences from known microorganisms, and three separate OLUs (C71, C107, and C115) (Figures 1, 4A). The clusters were dispersed all over the BchL/ChlL phylogeny although the majority of OLUs and reads grouped with ChlL from oxygenic photosynthetic organisms (Cyanobacteria and Trebouxiophyceae green algae) (Table 4 and Table S1, Figures 1, 4A, and Figure S4). Notably, a small number of cyanobacterial reads from samples KP2 and KP15 (cluster Phormidesmis priestleyi Ana-like), together with sequences mainly obtained from marine unicellular Cyanobacteria (Figure 4A and Table 4), grouped among proteobacterial BchL. This aberrant grouping was previously ascribed to the occurrence of several shared conserved signature indels, absent from ChlL of other Cyanobacteria (Gupta, 2012). The other clusters grouped with $\mathrm{BchL}$ of Chloroflexi and Proteobacteria or belonged to four clusters (BchL UT 1-4) that could not be assigned to a named phylum (Figure 4A). OLUs grouping with Chloroflexi were only retrieved from sample KP15 (Figure 4A and Table 4). Of the clusters grouping among proteobacterial BchL, most grouped with Alphaproteobacteria, some with Betaproteobacteria, and none was found grouping with Gammaproteobacteria (Figure 4A).

No clear psychrophilic association could be deduced from the habitat metadata of the nearest neighbors. Most BchL/ChlL sequences grouped together with sequences retrieved from samples taken in a variety of ecosystems worldwide (Table S2).

A total of $4950 \mathrm{BchX}$ sequences were obtained, many from sample KP43. They were binned at $95 \%$ protein similarity into 46 OXUs of which 31 were unique to one of the samples and 18 were singletons (Figure S3, Table 3, and Table S1). No OXU was found common between all four terrestrial samples (Figure S3). A single OXU, OXU C3, shared between samples KP15, KP43, and KP53, contained $82.10 \%$ of all BchX sequences and made up most of the reads retrieved from samples KP43 and KP53 (Figure 1, Table S1). However, phylogenetic analysis revealed that it did not group together with BchX sequences of known bacteria (Figure 4B). The less abundant OXUs C2 (3.68\%) and C32 (2.61\%) grouped in the same cluster as OXU C3 (BchX UT 1) and contained nearly exclusively sequences from sample KP43 (Table S1). OXU C1 (5.72\%), containing sequences from samples KP2, KP15, and KP43, grouped with the BchX sequence originating from Bradyrhizobium sp. S23321 (Table S1). All other OXUs represented less than $1 \%$ of $\mathrm{BchX}$ sequences.

Rarefaction analysis (Figure 2) indicated that saturation was not reached. The graph of sample KP53, however, started to flatten. This was also confirmed by the number of estimated OXUs, which was nearly identical to the number of observed OXUs for sample KP53 (Table 3). Evenness analysis resulted in very low values, except for sample KP2, which showed a more even distribution, although this could be explained by the very low number of sequences retrieved from this sample, grouping in seven OXUs (Table 3).

After ML analysis, 27 OXUs, of which 22 grouped in cluster BchX UT 1, could not be associated with a named phylum. The remaining 19 OXUs grouped with BchX sequences of 11 known bacterial taxa (Figure 4B) of Chloroflexi and Alpha-, Beta-, and Gammaproteobacteria, although the latter was represented by only one sequence (OXU C30) (Figure 4B, Table S1). For samples KP43 and KP53, however, most of the sequences and OXUs grouped in two clusters (BchX UT 1 and BchX UT 2) or separate OXUs that could not be associated with a known BchX reference sequence (Figure 1, Table 4, and Table S1).

Similar to PufM and BchL/ChlL, no clear grouping of BchX sequences from cold habitats could be seen, as our sequences grouped with sequences retrieved from a broad diversity of terrestrial and aquatic ecosystems worldwide (Table S2).

\section{DISCUSSION}

Given the distance to the ocean $(\sim 200 \mathrm{~km})$ and the extent of the surrounding ice cover, bacteria in exposed soils of the Sør Rondane Mountains, East Antarctica, are faced with very low availability of organic matter (Osanai et al., 2013; Zazovskaya et al., 2015; Tytgat et al., 2016) and might thus be expected to use alternative energy sources such as sunlight. During an initial survey using libraries of $\sim 100$ clones, phototrophy genes were investigated for the first time in this terrestrial Antarctic location (Tahon et al., 2016). Analysis of partial PufM sequences revealed diversity predominantly associated with phylotypes from aerobic anoxygenic photoheterotrophic 


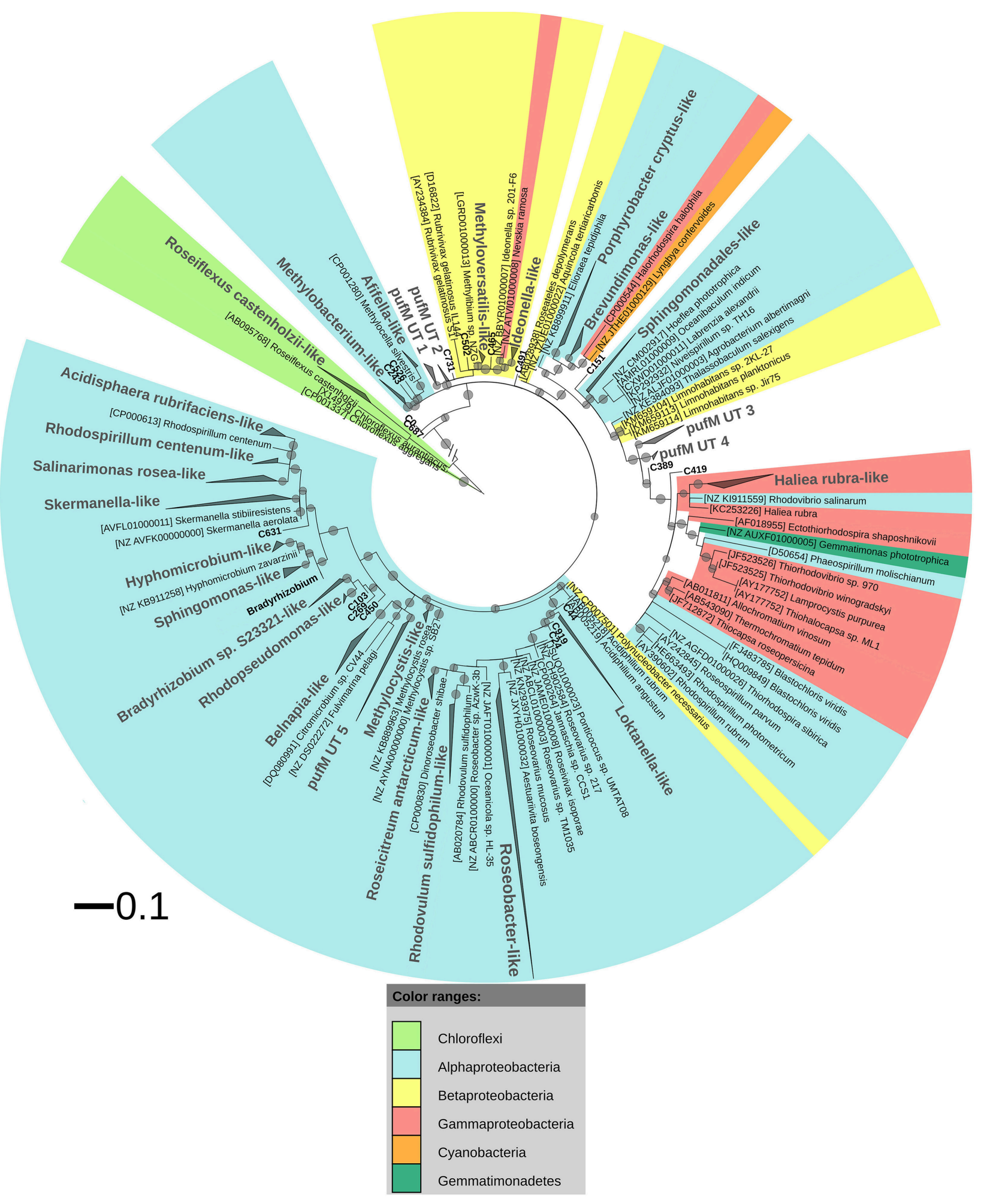

FIGURE 3 | ML phylogenetic tree (1000 bootstrap replicates) of PufM sequences. Scale bar indicates 0.1 substitutions per amino acid position. OPU clusters (larger font size) were named after cultivated bacteria that grouped in or close to the cluster. In the absence of cultivated members, clusters were given an Utsteinen (UT) cluster number designation. For clusters, the total branch lengths to the closest and farthest leaf of the cluster were used as sides of the triangle. OPUs not enclosed in clusters are labeled in bold. For reference data, taxon name, and accession number is listed. Bootstrap values are displayed as circles with a diameter reflecting the height of the bootstrap value. Smallest circles represent the lower cut-off of $70 \%$. Chloroflexi PufM sequences were used as an outgroup. PufM sequences originating from cultured Bradyrhizobium species were grouped in the cluster defined as "Bradyrhizobium" to simplify the topology of the tree. 
TABLE 4 | Distribution of OTUs (95\% protein similarity) and reads per PufM, BchL/ChIL, or BchX cluster or separate OTU.

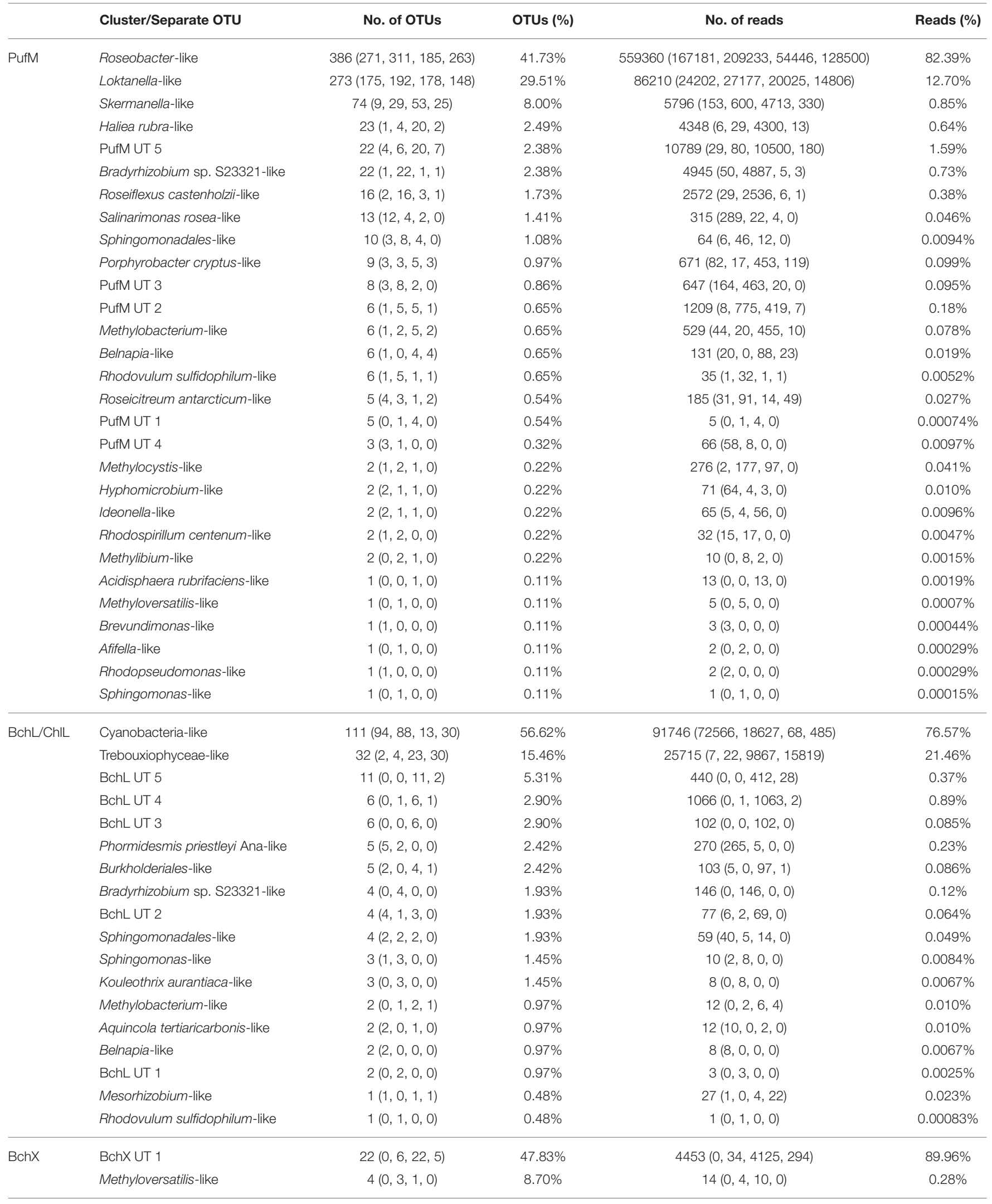




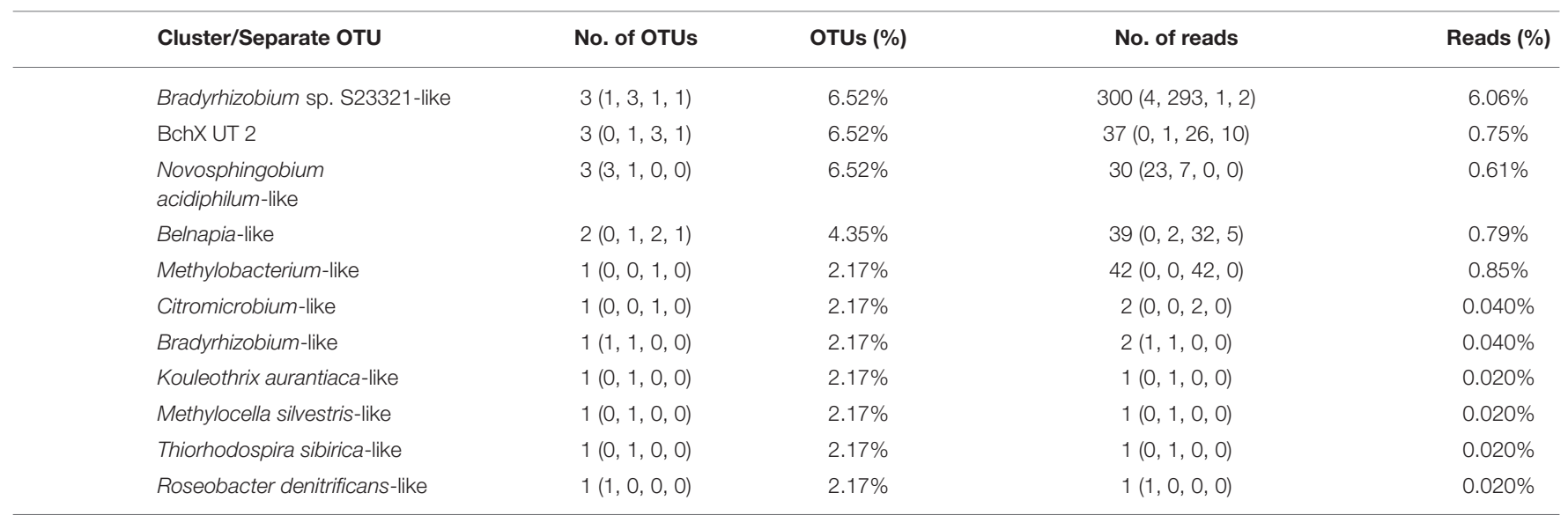

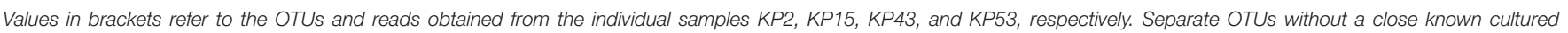
representative are not included. For the Cyanobacteria/Trebouxiophyceae-like ChIL cluster Cyanobacteria-like and Trebouxiophyceae-like sequences are listed separately.

Alphaproteobacteria. The most abundant ion pumping microbial rhodopsin gene family, proteorhodopsin, however, could not be amplified from the samples (Tahon et al., 2016). In the present study we used high-throughput Illumina MiSeq paired-end 300 bp sequencing to more comprehensively study the presence and diversity of genes involved in light-harvesting, in the same samples.

To target a wider diversity of anoxygenic phototrophs using the photosynthetic type 2 reaction center, the more universal pufM_uniF/pufM_WAW primer set (Yutin et al., 2005) was used. Using our pufLM database assembled from publicly available sequences, an in silico comparison of these primers with other less degenerate primers (i.e., pufM_557F, pufMR and pufM_750R) used in other studies (Nagashima et al., 1997; Achenbach et al., 2001) clearly showed that the Yutin et al. primer set (Yutin et al., 2005) targets a much wider pufM diversity (Figure S5). In addition, contrary to the clone library results (Tahon et al., 2016), the primer set used here gave successful amplification in all samples. As observed in the clone libraries, alphaproteobacterial-like PufM sequences were most frequently recovered (98.60\%), followed distantly by gammaproteobacterial-like sequences (0.64\%). Deep sequencing also revealed presence of some betaproteobacteriallike $(0.012 \%)$ and even chloroflexi-like (0.38\%) PufM (Figure 3). The dominance of alphaproteobacterial PufM sequences has been previously observed in the Arctic (Feng et al., 2014) and Antarctic (Karr et al., 2003; Koh et al., 2011), whereas chloroflexi-like PufM sequences have not previously been reported from polar or most other environments studied so far. Also in Arctic soils (Feng et al., 2014), gammaproteobacterial-like PufM sequences were found to contribute less to the general diversity.

The relative abundance of Roseobacter-like and Loktanellalike PufM in our samples is remarkably high (Figure 1). PufM from these two AAP-containing taxa have previously nearly exclusively been reported from marine and saline lake environments from polar and non-polar regions (Van Trappen et al., 2004; Oz et al., 2005; Du et al., 2006; Yutin et al., 2008; Cottrell and Kirchman, 2009; Jiang et al., 2010; Jeanthon et al., 2011; Koh et al., 2011; Ritchie and Johnson, 2012; Ferrera et al., 2014). The high relative abundance of Roseobacterlike PufM sequences $(82.39 \%)$ in our terrestrial samples is therefore striking. Roseobacter has been found to be important in sulfur cycling in aquatic environments (González and Moran, 1997; Buchan et al., 2005; Wagner-Döbler and Biebl, 2006). However, the absence of Roseobacter 16S rRNA sequences in this study area (Tytgat et al., 2016) and in terrestrial Antarctic systems in general (based on metagenome data available in NCBI, MG-RAST, Wilke et al., 2016 and IMG/M Markowitz et al., 2014) suggests the presence of other microorganisms, containing PufM highly similar to that of Roseobacter, in our samples. The remainder of the PufM diversity in our samples, although recovered in small relative numbers, also mainly related to aquatic photoheterotrophic taxa. However, several of the PufM sequences recovered (e.g., Methylobacterium-like, Rhodopseudomonas-like) were highly similar to PufM reported from Arctic soils (Feng et al., 2014) or Chinese paddy soils (Feng et al., 2009, 2011a,b,c). Thus, although aerobic anoxygenic phototrophy is frequently studied in aquatic environments, our data strongly suggest that this lifestyle may potentially be important in terrestrial ecosystems.

The primers (Ando et al., 2005) previously used to amplify a broad diversity of nifH sequences also amplified structurally similar oxidoreductase subunits involved in (bacterio)chlorophyll synthesis (bchL/chlL encoding for the $\mathrm{L}$ subunit of DPOR in APB, Cyanobacteria, green algae, and lower land plants, and $b c h X$ encoding for a COR subunit of APB). The high relative abundance $(98.26 \%)$ of cyanobacterial plus Trebouxiophyceae green algal ChlL suggested an important role for oxygenic photosynthetic organisms in our samples (Table 4, Figure 4A, and Figure S4). Notably, an inverse pattern was observed: nearly all of the ChlL reads recovered from samples KP2 (99.89\%) and KP15 (98.92\%) grouped with Chroococcales and Oscillatoriales Cyanobacteria, respectively (Table S1), with very few Trebouxiophyceae-like sequences $(<0.12 \%)$. KP43 and KP53, on the other hand, contained far less cyanobacterial reads ( 0.58 and $2.96 \%$ respectively) and a very high relative abundance 
of Trebouxiophyceae-like ChlL (84.23 and $96.69 \%$ respectively) (Figure 1, Table S1). A similar pattern was observed previously (Tahon et al., 2016, under review): a high relative abundance of both cyanobacterial cbbL type IB (RuBisCO) and 16S rRNA, grouping with Chroococcales and Oscillatoriales Cyanobacteria, was recorded from the KP2 and KP15 samples, respectively, and much less in KP43 and KP53. A high relative number of trebouxiophyceael chloroplast $16 \mathrm{~S}$ rRNA sequences was recorded from the latter samples (Tahon et al., under review).
However, as the primers were originally designed to amplify a broad diversity of nifH (Ando et al., 2005), and not bchL/chlL, it is conceivable that they might show a bias toward particular groups. Therefore, an in silico analysis, using a broad diversity of publicly available sequences, was performed to investigate possible primer bias. The IGK3 and DVV primers (Ando et al., 2005, Table 2) generally showed one or two mismatches, located at the $5^{\prime}$ primer end, with $b c h L / c h l L$ reference data of different phyla (Figure S5). Chlorobi sequences, however, showed most

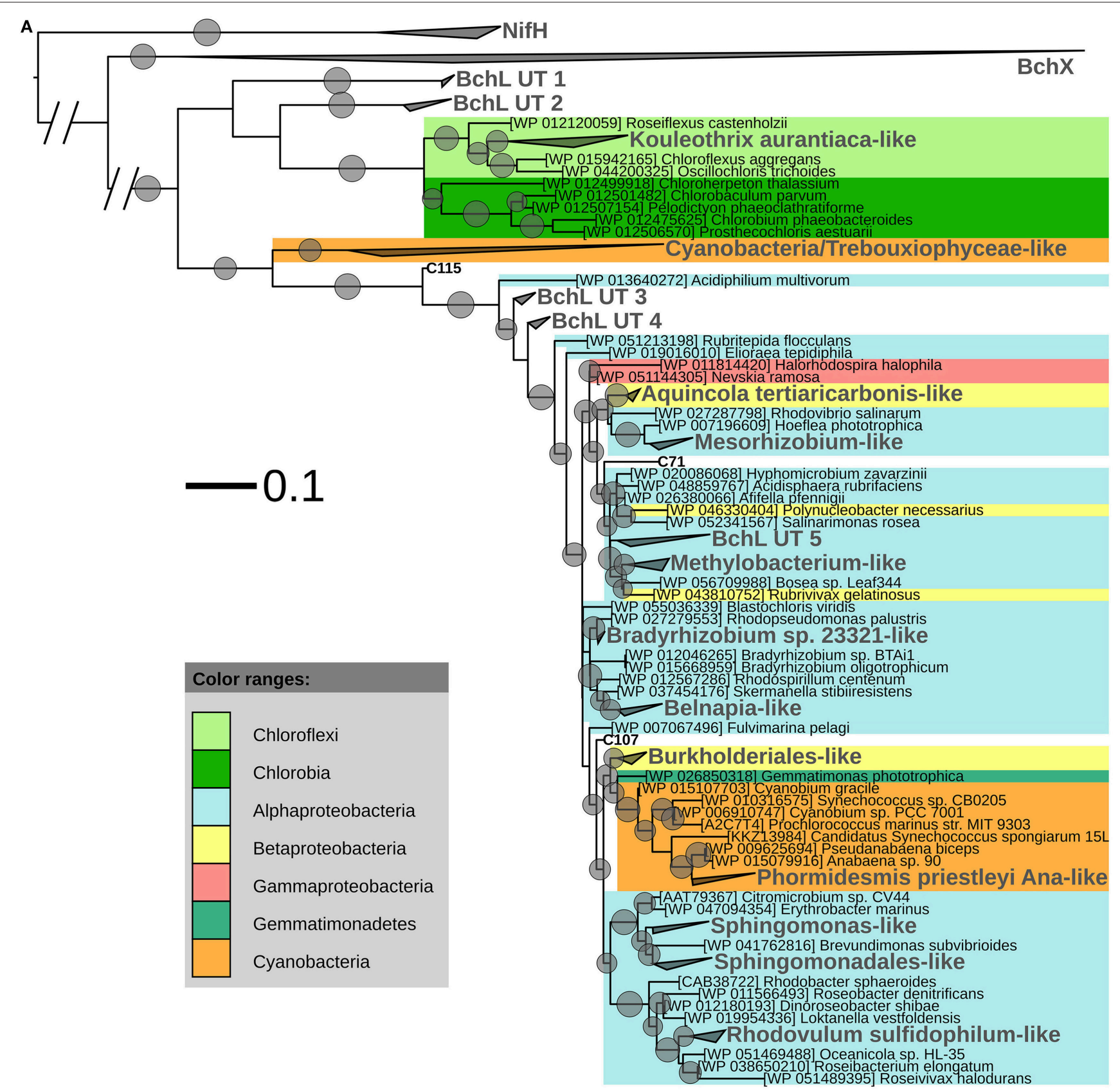

FIGURE 4 | Continued 


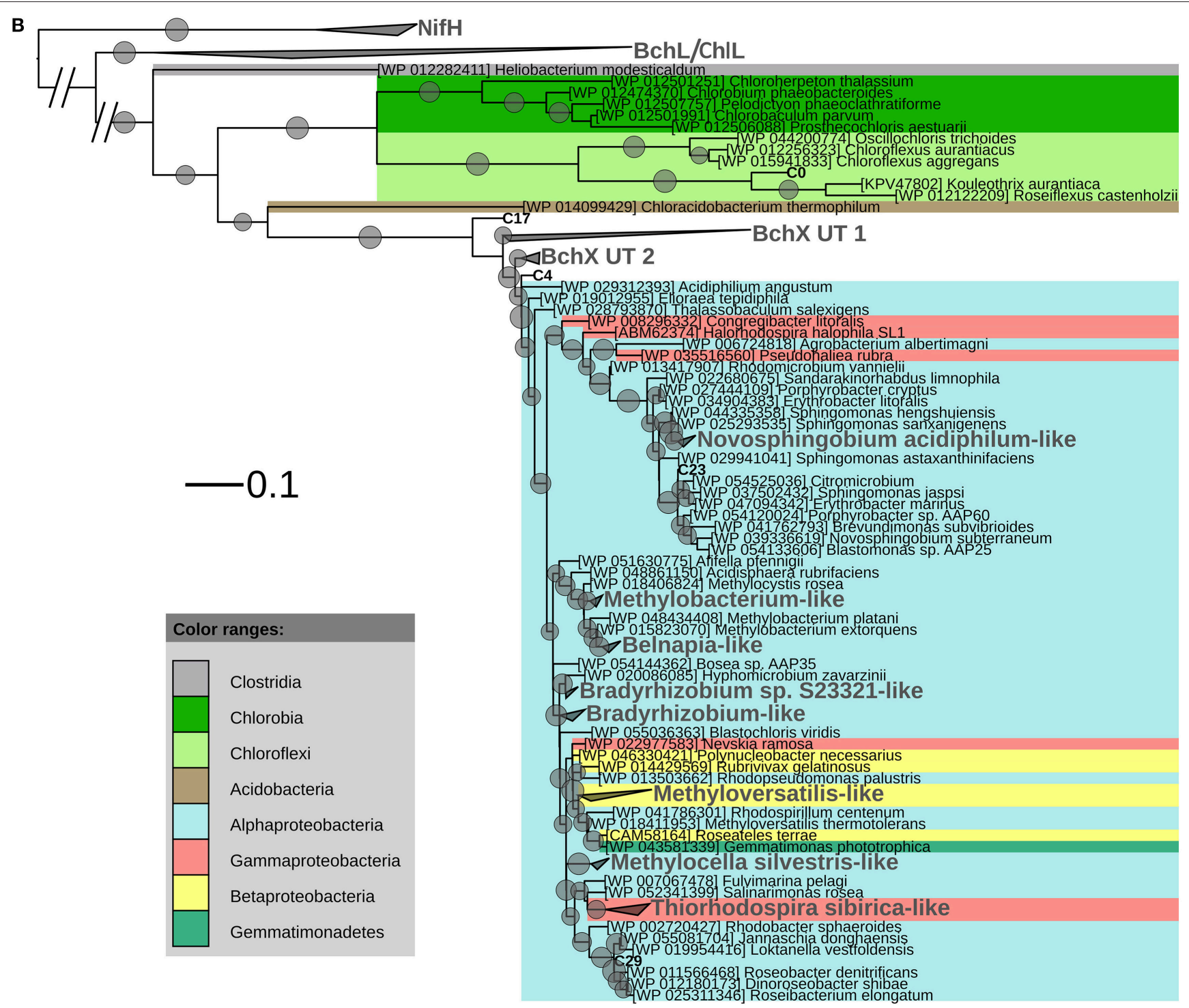

FIGURE 4 | (A) ML phylogenetic tree (1000 bootstraps) of BchL/ChlL sequences. NifH sequences were used as an outgroup. Scale bar indicates 0.1 substitutions per amino acid position. OLU clusters (larger font size, labeled in gray) were named after cultivated bacteria that grouped in or close to the cluster. In the absence of cultivated members, clusters were given an Utsteinen (UT) cluster number designation. For clusters, the total branch lengths to the closest and farthest leaf of the cluster were used as sides of the triangle. OLUs not enclosed in clusters are labeled in bold. For reference data, taxon name and accession number is listed. Bootstrap values of at least $70 \%$ are displayed as circles with a diameter reflecting the height of the bootstrap value. BchX sequences are shown as a single cluster (details given in B). (B). BchX ML phylogenetic tree (1000 bootstraps). NifH sequences were used as an outgroup. Scale bar indicates 0.1 substitutions per amino acid position. OXUs not enclosed in a cluster are labeled in bold. OXU clusters (larger font size, labeled in gray) were named after cultivated bacteria that grouped in or close to the cluster. In the absence of cultivated members, clusters were given an Utsteinen (UT) cluster number designation. For clusters, the total branch lengths to the closest and farthest leaf of the cluster were used as sides of the triangle. For reference data, taxon name, and accession number is listed. Bootstrap values of at least $70 \%$ are displayed as circles. Smallest circles represent the lower cut-off of $70 \%$ with a diameter reflecting the height of the bootstrap value. BchL/ChlL sequences are shown as a single cluster (details given in $\mathbf{A}$ ).

mismatches (four and one in DVV and IGK3, respectively). The absence of clear differences in primer specificity for different groups suggests there is unlikely to be extensive bias in the primers. Thus, the high relative abundance of oxygenic photosynthetic microorganisms in ChlL suggests they indeed appear to be an important phototrophic group in the investigated samples.
In addition to the highly recovered cyanobacterial and green algal ChlL, a small number of non-cyanobacterial BchL sequences (1.74\%-2091 sequences, including 25 singletons) grouped with a broad diversity of mainly aerobic anoxygenic phototrophic bacteria primarily belonging to alphaproteobacterial taxa and to lesser extent betaproteobacterial and chloroflexi taxa (Figure 4A). 
The IGK3 and DVV primers also amplify $b c h X$. Because this gene is not present in Cyanobacteria or in Trebouxiophyceae, the BchX dataset was relatively small (4950 sequences). The alternative explanation that primer mismatch might have reduced the number of sequences recovered, is less likely. Indeed, in silico analysis showed that the number of mismatches with a set of representative $b c h X$ sequences was limited (Figure S5). The low number of sequences precludes firm conclusions regarding $\mathrm{BchX}$ diversity. The $\mathrm{BchX}$ sequences mainly grouped with alphaproteobacterial taxa and to a lesser extent with Betaproteobacteria, Gammaproteobacteria, and Chloroflexi (Figure 4B), however, with greater sequencing depth, relative abundances may change. Most of the BchX reads grouped into two clusters (BchX UT 1 and 2) without any close known representative, indicating the existence of multiple not yet cultured or recognized APB. Indeed many anoxygenic phototrophs can grow heterotrophically and it is thus possible that some taxa, originally described as regular heterotrophs, may have phototrophic capacities that have not been noticed. Indeed, Salinarimonas rosea DSM 21201 originally tested negative for bacteriochlorophyll $a$ synthesis (Liu et al., 2010) and the phototrophic capacities of Skermanella stibiiresistens SB22 were originally not reported (Luo et al., 2012), whereas more recent analysis of their genomic sequences (accession numbers AUBC01000000 and AVFL01000000) revealed their phototrophic potential.

Finally, since BchL/ChlL, BchX, and NifH exhibit a high degree of protein sequence similarity (Raymond et al., 2004), and their genes can be retrieved using the same primer set, it may be a challenge to correctly annotate these sequences. During our analyses, we noticed that public databases contain several BchL/ChlL and BchX sequences annotated as $\mathrm{NifH}$, and vice versa. When studying these genes and including reference data, it is therefore important to take into account gene specific conserved amino acid positions to ensure correct interpretation of data.

Comparing the datasets for different genes is difficult as datasets obtained with different primers cannot be compared directly because of differences in primer specificity, PCR efficiency or bias. Nevertheless, because the large sampling depth of PufM complicates evaluation, we have normalized PufM and BchL/ChlL datasets (Table 3) to tentatively allow a rough comparison. This shows that pufM diversity is somewhat lower though of similar magnitude than that of BchL/ChlL (171 OPUs-192 OLUs). It should be noted that horizontal gene transfer may cause discrepancies between phylogenies of $16 \mathrm{~S}$ rRNA or $c b b L$, and photosynthesis genes (Igarashi et al., 2000). However, tentatively, it can be noted that several of the APB taxa retrieved here were previously reported from 16S rRNA (e.g., Bradyrhizobium, Sphingomonas, Afifella, Methylibium) and $c b b L$ (RuBisCO) (e.g., Mesorhizobium, Bradyrhizobium, Methyloversatilis, Rhodospirillum centenum) clone library and Illumina sequencing results from the same samples (Tahon et al., 2016, under review). Interestingly, the relative abundance of Bradyrhizobium-related sequences from sample KP15 was much higher than from the other samples in the three photosynthetic datasets (Table 4), as well as the $16 \mathrm{~S}$ rRNA and cbbL datasets
(Tahon et al., 2016) [Tahon et al., under review]. Furthermore, the genome of Bradyrhizobium sp. S23321 - the closest neighbor to most of our Bradyrhizobium-related sequences-revealed a gene content adapted to survival in a broad range of environments (Okubo et al., 2006). The combination of these data thus suggests photoautotrophic bradyrhizobia may be present in sample KP15.

In the pilot study proteorhodopsin could not be detected (Tahon et al., 2016). Actinorhodopsin, a similar lightdriven proton pump, was originally retrieved from aquatic Actinobacteria (Sharma et al., 2008) and little is known about its presence in terrestrial environments. Because Illumina data of partial 16S rRNA genes previously showed the samples investigated here to contain diverse Actinobacteria (6.26-23.48\% of reads and 20.73-34.60\% of OTUs, Tytgat et al., 2016) [Tahon et al., under review], we used several primer sets (Table 2) to amplify actinorhodopsin genes from our samples. While our attempts failed, this does not necessarily imply that these systems are absent in the terrestrial Antarctic bacterial communities. Currently available primers may be unsuitable to capture all actinorhodopsin diversity, as most reference data originates from aquatic systems (Sharma et al., 2008, 2009; Wurzbacher et al., 2012; Jezberová et al., 2013; Salka et al., 2014). Future metagenome datasets may resolve this question.

\section{CONCLUSIONS}

We studied the presence of bacterial phototrophic pathways in a terrestrial Antarctic environment. While we could not detect actinorhodopsin genes, our analysis of other genes showed that a broad variety of oxygenic and anoxygenic phototrophs is present in soils of the Sør Rondane Mountains, East Antarctica. The high relative abundance of oxygenic photosynthetic microorganisms, however, suggests they are an important phototrophic group. Sequencing results of BchL, ChlL, and BchX, involved in (bacterio)chlorophyll synthesis, were dominated either by Cyanobacteria- or Trebouxiophyceaerelated sequences. Moreover, the presence of currently unknown non-cyanobacterial phylotypes suggests the existence of multiple not yet cultured or recognized anoxygenic phototrophic bacteria. Illumina Miseq sequencing of PufM, typical for light-harvesting bacteria with a type 2 reaction center, revealed a very high relative abundance of two groups of sequences, i.e., Roseobacter-like and Loktanella-like, and a large diversity of other less abundant taxa from Alpha-, Beta-, and Gammaproteobacteria, Chloroflexi and several unassigned groups. Although photoheterotrophic bacterial light-harvesting is nearly exclusively studied in aquatic environments, our results suggest the potential relevance of this mechanism in terrestrial ecosystems.

\section{AUTHOR CONTRIBUTIONS}

Conceived and designed the experiments: GT, AW. Performed the experiments: GT. Analyzed the data: GT, BT. Contributed analysis tools: BT. Wrote the paper: GT, AW. All authors approved the final manuscript. 


\section{ACKNOWLEDGMENTS}

This work was supported by the Fund for Scientific ResearchFlanders (project G.0146.12). Additional support was obtained from the Belgian Science Policy Office (project CCAMBIO). The computational resources (Stevin Supercomputer Infrastructure) and services used in this work were provided by the Flemish Supercomputer Center (VSC) funded by Ghent University, the Hercules Foundation and the Flemish Government-department

\section{REFERENCES}

Achenbach, L. A., Carey, J., and Madigan, M. T. (2001). Photosynthetic and phylogenetic primers for detection of anoxygenic phototrophs in natural environments. Appl. Environ. Microbiol. 67, 2922-2926. doi: 10.1128/AEM.67.7.2922-2926.2001

Ando, S., Goto, M., Meunchang, S., Thongra-Ar, P., Fujiwara, T., Hayashi, H., et al. (2005). Detection of nifH sequences in sugarcane (Saccharum officinarum L.) and pineapple (Ananas comosus [L.] Merr.). Soil Sci. Plant Nutr. 51, 303-308. doi: 10.1111/j.1747-0765.2005.tb00034.x

Beale, S. I. (1999). Enzymes of chlorophyll biosynthesis. Photosyn. Res. 60, 43-73. doi: 10.1023/A:1006297731456

Béjà, O., and Lanyi, J. K. (2014). Nature's toolkit for microbial rhodopsin ion pumps. Proc. Natl. Acad. Sci. U.S.A. 111, 6538-6539. doi: $10.1073 /$ pnas.1405093111

Béjà, O., Spudich, E. N., Spudich, J. L., Leclerc, M., and Delong, E. F. (2001). Proteorhodopsin phototrophy in the ocean. Nature 411, 786-789. doi: $10.1038 / 35081051$

Boeuf, D., Audic, S., Brillet-Guéguen, L., Caron, C., and Jeanthon, C. (2015). MicRhoDE: a curated database for the analysis of microbial rhodopsin diversity and evolution. Database 2015:bav080. doi: 10.1093/database/bav080

Bryant, D. A., and Frigaard, N.-U. (2006). Prokaryotic photosynthesis and phototrophy illuminated. Trends Microbiol. 14, 488-496. doi: 10.1016/j.tim.2006.09.001

Buchan, A., González, J. M., and Moran, M. A. (2005). Overview of the marine roseobacter lineage. Appl. Environ. Microbiol. 71, 5665-5677. doi: 10.1128/AEM.71.10.5665-5677.2005

Butterfield, N. J. (2015). Proterozoic photosynthesis - a critical review. Palaeontology 58, 953-972. doi: 10.1111/pala.12211

Cardona, T. (2016). Reconstructing the origin of oxygenic photosynthesis: do assembly and photoactivation recapitulate evolution? Front. Plant Sci. 7:257. doi: $10.3389 /$ fpls.2016.00257

Cary, S. C., McDonald, I. R., Barrett, J. E., and Cowan, D. A. (2010). On the rocks: the microbiology of antarctic dry valley soils. Nature Rev. Microbiol. 8, 129-138. doi: $10.1038 /$ nrmicro2281

Chew, A. G., and Bryant, D. A. (2007). Chlorophyll biosynthesis in bacteria: the origins of structural and functional diversity. Annu. Rev. Microbiol. 61, 113-129. doi: 10.1146/annurev.micro.61.080706.093242

Convey, P., Gibson, J. A., Hillenbrand, C.-D., Hodgson, D. A., Pugh, P. J., Smellie, J. L., et al. (2008). Antarctic terrestrial life - challenging the history of the frozen continent? Biol. Rev. 83, 103-117. doi: 10.1111/j.1469-185X.2008. 00034.x

Cottrell, M. T., and Kirchman, D. L. (2009). Photoheterotrophic microbes in the arctic ocean in summer and winter. Appl. Environ. Microbiol. 75, 4958-4966. doi: 10.1128/AEM.00117-09

Cowan, D. A., Makhalanyane, T. P., Dennis, P. G., and Hopkins, D. W. (2014). Microbial ecology and biogeochemistry of continental antarctic soils. Front. Microbiol. 5:154. doi: 10.3389/fmicb.2014.00154

Dixon, P. (2003). VEGAN, a package of R functions for community ecology. J. Vegetation Sci. 14, 927-930. doi: 10.1111/j.1654-1103.2003.tb02228.x

Do, H., Kim, S.-J., Kim, H. J., and Lee, J. H. (2014). Structure-based characterization and antifreeze properties of a hyperactive ice-binding protein from the Antarctic bacterium Flavobacterium frigoris PS1. Acta Crystallogr. D 70, 1061-1073. doi: 10.1107/S1399004714000996
EWI. This study is a contribution to the State of the Antarctic Ecosystem (AntEco) research program of the Scientific Committee on Antarctic Research (SCAR).

\section{SUPPLEMENTARY MATERIAL}

The Supplementary Material for this article can be found online at: http://journal.frontiersin.org/article/10.3389/fmicb. 2016.02026/full\#supplementary-material

Du, H., Jiao, N., Hu, Y., and Zeng, Y. (2006). Real-time PCR for quantification of aerobic anoxygenic phototrophic bacteria based on pufM gene in marine environment. J. Exp. Mar. Biol. Ecol. 329, 113-121. doi: 10.1016/j.jembe.2005.08.009

Edgar, R. C. (2010). Search and clustering orders of magnitude faster than BLAST. Bioinformatics 26, 2460-2461. doi: 10.1093/bioinformatics/btq461

Edgar, R. C., Haas, B. J., Clemente, J. C., Quince, C., and Knight, R. (2011). UCHIME improves sensitivity and speed of chimera detection. Bioinformatics 27, 2194-2200. doi: 10.1093/bioinformatics/btr381

Feng, Y., Grogan, P., Caporaso, J. G., Zhang, H., Lin, X., Knight, R., et al. (2014). $\mathrm{pH}$ is a good predictor of the distribution of anoxygenic purple phototrophic bacteria in Arctic soils. Soil Biol. Biochem. 74, 193-200. doi: 10.1016/j.soilbio.2014.03.014

Feng, Y., Lin, X., Mao, T., and Zhu, J. (2011a). Diversity of aerobic anoxygenic phototrophic bacteria in paddy soil and their response to elevated atmospheric CO2. Microb. Biotechnol. 4, 74-81. doi: 10.1111/j.1751-7915.2010.00211.x

Feng, Y., Lin, X., Wang, Y., Zhang, J., Mao, T., Yin, R., et al. (2009). Free-air CO2 enrichment (FACE) enhances the biodiversity of purple phototrophic bacteria in flooded paddy soil. Plant Soil 324, 317-328. doi: 10.1007/s11104-0099959-3

Feng, Y., Lin, X., Yu, Y., and Zhu, J. (2011b). Elevated ground-level O-3 changes the diversity of anoxygenic purple phototrophic bacteria in paddy field. Microb. Ecol. 62, 789-799. doi: 10.1007/s00248-011-9895-7

Feng, Y., Lin, X., Zhang, J., Mao, T., and Zhu, J. (2011c). Soil purple phototrophic bacterial diversity under double cropping (rice-wheat) with free-air CO2 enrichment (FACE). Eur. J. Soil Sci. 62, 533-540. doi: 10.1111/j.1365-2389.2011.01357.x

Ferrera, I., Borrego, C. M., Salazar, G., and Gasol, J. M. (2014). Marked seasonality of aerobic anoxygenic phototrophic bacteria in the coastal NW Mediterranean Sea as revealed by cell abundance, pigment concentration and pyrosequencing of pufM gene. Environ. Microbiol. 16, 2953-2965. doi: 10.1111/1462-2920.12278

Fu, L., Niu, B., Zhu, Z., Wu, S., and Li, W. (2012). CD-HIT: accelerated for clustering the next-generation sequencing data. Bioinformatics 28, 3150-3152. doi: 10.1093/bioinformatics/bts565

Fujita, Y., and Bauer, C. E. (2003). "The light-independent protochlorophyllide reductase: a nitrogenase-like enzyme catalyzing a key reaction for greening in the dark," in The Porphyrin Handbook, eds R. Guilard, K. Kadish, and K. M. Smith (Amsterdam: Academic Press), 109-156.

González, J. M., and Moran, M. A. (1997). Numerical dominance of a group of marine bacteria in the alpha-subclass of the class Proteobacteria in coastal seawater. Appl. Environ. Microbiol. 63, 4237-4242.

Gotelli, N. J., and Colwell, R. K. (2010). "Estimating species richness," in Biological Diversity: Frontiers in Measurement and Assessment, eds A. E. Magurran and B. J. McGill (Oxford: Oxford University Press), 39-54.

Goujon, M., McWilliam, H., Li, W., Valentin, F., Squizzato, S., Paern, J., et al. (2010). A new bioinformatics analysis tools framework at EMBL-EBI. Nucleic Acids Res. 38, W695-W699. doi: 10.1093/nar/gkq313

Gupta, R. S. (2012). Origin and spread of photosynthesis based upon conserved sequence features in key bacteriochlorophyll biosynthesis proteins. Mol. Biol. Evol. 29, 3397-3412. doi: 10.1093/molbev/mss 145

Harashima, K., Shiba, T., Totsuka, T., Simidu, U., and Taga, N. (1978). Occurrence of bacteriochlorophyll a in a strain of an aerobic heterotrophic bacterium. Agric. Biol. Chem. 42, 1627-1628. doi: 10.1271/bbb1961.42.1627 
Hohmann-Marriott, M. F., and Blankenship, R. E. (2011). Evolution of photosynthesis. Annu. Rev. Plant Biol. 62, 515-548. doi: 10.1146/annurev-arplant-042110-103811

Igarashi, N., Harada, J., Nagashima, S., Matsuura, K., Shimada, K., and Nagashima, K. V. (2000). Horizontal transfer of the photosynthesis gene cluster and operon rearrangement in purple bacteria. J. Mol. Evol. 52, 333-341. doi: $10.1007 / \mathrm{s} 002390010163$

Jeanthon, C., Boeuf, D., Dahan, O., Le Gall, F., Garczarek, L., Bendif, E. M., et al. (2011). Diversity of cultivated and metabolically active aerobic anoxygenic phototrophic bacteria along an oligotrophic gradient in the Mediterranean Sea. Biogeosciences 8, 1955-1970. doi: 10.5194/bg-8-1955-2011

Jezberová, J., Jezbera, J., and Hahn, M. W. (2013). Insights into variability of actinorhodopsin genes of the LG1 cluster in two different freshwater habitats. PLOS ONE 8:e68542. doi: 10.1371/journal.pone.0068542

Jiang, H., Deng, S., Huang, Q., Dong, H., and Yu, B. (2010). Response of aerobic anoxygenic phototrophic bacterial diversity to environment conditions in saline lakes and daotang river on the Tibetan Plateau, NW China. Geomicrobiol. J. 27, 400-408. doi: 10.1080/01490450903480269

Karr, E. A., Sattley, W. M., Jung, D. O., Madigan, M. T., and Achenbach, L. A. (2003). Remarkable diversity of phototrophic purple bacteria in a permanently frozen antarctic lake. Appl. Environ. Microbiol. 69, 4910-4914. doi: 10.1128/AEM.69.8.4910-4914.2003

Kauserud, H., Kumar, S., Brysting, A. K., Nordén, J., and Carlsen, T. (2012). High consistency between replicate 454 pyrosequencing analyses of ectomycorrhizal plant root samples. Mycorrhiza 22, 309-315. doi: 10.1007/s00572-011-0403-1

Kennedy, A. D. (1993). Water as a limiting factor in the Antarctic terrestrial environment - a biogeographical synthesis. Arctic Alpine Res. 25, 308-315. doi: $10.2307 / 1551914$

Kobližek, M. (2015). Ecology of aerobic anoxygenic phototrophs in aquatic environments. FEMS Microbiol. Rev. 39, 854-870. doi: 10.1093/femsre/fuv032

Koh, E. Y., Atamna-Ismaeel, N., Martin, A., Cowie, R. O., Béjà, O., Davy, S. K., et al. (2010). Proteorhodopsin-bearing bacteria in Antarctic sea ice. Appl. Environ. Microbiol. 76, 5918-5925. doi: 10.1128/AEM.00562-10

Koh, E. Y., Phua, W., and Ryan, K. G. (2011). Aerobic anoxygenic phototrophic bacteria in Antarctic sea ice and seawater. Environ. Microbiol. Rep. 3, 710-716. doi: 10.1111/j.1758-2229.2011.00286.x

Letunic, I., and Bork, P. (2007). Interactive Tree Of Life (iTOL): an online tool for phylogenetic tree display and annotation. Bioinformatics 23, 127-128. doi: 10.1093/bioinformatics/bt1529

Letunic, I., and Bork, P. (2011). Interactive tree of life v2: online annotation and display of phylogenetic trees made easy. Nucleic Acids Res. 39, W475-W478. doi: $10.1093 / \mathrm{nar} / \mathrm{gkr} 201$

Li, W., and Godzik, A. (2006). Cd-hit: a fast program for clustering and comparing large sets of protein or nucleotide sequences. Bioinformatics 22, 1658-1659. doi: 10.1093/bioinformatics/btl158

Liu, J.-H., Wang, Y.-X., Zhang, X.-X., Wang, Z.-G., Chen, Y.-G., Wen, M.-L., et al. (2010). Salinarimonas rosea gen. nov., sp. nov., a new member of the $\alpha-2$ subgroup of the proteobacteria. Int. J. Syst. Evol. Microbiol. 60, 55-60. doi: 10.1099/ijs.0.006981-0

Logares, R., Audic, S., Bass, D., Bittner, L., Boutte, C., Christen, R., et al. (2014). Patterns of rare and abundant marine microbial eukaryotes. Curr. Biol. 24, 813-821. doi: 10.1016/j.cub.2014.02.050

Luo, G., Shi, Z., Wang, H., and Wang, G. (2012). Skermanella stibiiresistens sp. nov., a highly antimony-resistant bacterium isolated from coal-mining soil, and emended description of the genus Skermanella. Int. J. Syst. Evol. Microbiol. 62, 1271-1276. doi: 10.1099/ijs.0.033746-0

Markowitz, V. M., Chen, I. M., Chu, K., Szeto, E., Palaniappan, K., Pillay, M., et al. (2014). IMG/M 4 version of the integrated metagenome comparative analysis system. Nucleic Acids Res. 42, D568-D573. doi: 10.1093/nar/gkt919

Markowitz, V. M., Chen, I. M., Palaniappan, K., Chu, K., Szeto, E., Grechkin, Y., et al. (2012). IMG: the integrated microbial genomes database and comparative analysis system. Nucleic Acids Res. 40, D115-D122. doi: 10.1093/nar/ gkr1044

Martin, M. (2011). Cutadapt removes adapter sequences from high-throughput sequencing reads. EMBnet.journal 17, 10. doi: 10.14806/ej.17.1.200

McMurdie, P. J., and Holmes, S. (2014). Waste not, want not: why rarefying microbiome data is inadmissible. PLoS Comput. Biol. 10:e1003531. doi: 10.1371/journal.pcbi.1003531
Nagashima, K. V., Hiraishi, A., Shimada, K., and Matsuura, K. (1997). Horizontal transfer of genes coding for the photosynthetic reaction centers of purple bacteria. J. Mol. Evol. 45, 131-136. doi: 10.1007/PL00006212

Nomata, J., Kondo, T., Mizoguchi, T., Tamiaki, H., Itoh, S., and Fujita, Y. (2014). Dark-operative protochlorophyllide oxidoreductase generates substrate radicals by an iron-sulphur cluster in bacteriochlorophyll biosynthesis. Sci. Rep. 4:5455. doi: 10.1038/srep05455

Obbels, D., Verleyen, E., Mano, M.-J., Namsaraev, Z., Sweetlove, M., Tytgat, B., et al. (2016). Bacterial and eukaryotic biodiversity patterns in terrestrial and aquatic habitats in the Sør Rondane Mountains, Dronning Maud Land, East Antarctica. FEMS Microbiol. Ecol. 92:fiw041. doi: 10.1093/femsec/fiw041

Okubo, Y., Futamata, H., and Hiraishi, A. (2006). Characterization of phototrophic purple nonsulfur bacteria forming colored microbial mats in a swine wastewater ditch. Appl. Environ. Microbiol. 72, 6225-6233. doi: 10.1128/AEM.00796-06

Osanai, Y., Nogi, Y., Baba, S., Nakano, N., Adachi, T., Hokada, T., et al. (2013). Geologic evolution of the Sør Rondane Mountains, East Antarctica: collision tectonics proposed based on metamorphic processes and magnetic anomalies. Precambrian Res. 234, 8-29. doi: 10.1016/j.precamres.2013.05.017

Oz, A., Sabehi, G., Koblízek, M., Massana, R., and Béjà, O. (2005). Roseobacter-like bacteria in red and mediterranean sea aerobic anoxygenic photosynthetic populations. Appl. Environ. Microbiol. 71, 344-353. doi: 10.1128/AEM.71.1.344-353.2005

Pascual, J., Blanco, S., García-López, M., García-Salamanca, A., Bursakov, S. A., Genilloud, O., et al. (2016). Assessing bacterial diversity in the rhizosphere of Thymus zygis growing in the sierra nevada national park (Spain) through culture-dependent and independent approaches. PLOS ONE 11:e0146558. doi: 10.1371/journal.pone. 0146558

Pedrós-Alió, C. (2012). The rare bacterial biosphere. Ann. Rev. Mar. Sci. 4, 449-466. doi: 10.1146/annurev-marine-120710-100948

Petrovskaya, L. E., Lukashev, E. P., Chupin, V. V., Sychev, S. V., Lyukmanova, E. N., Kryukova, E. A., et al. (2010). Predicted bacteriorhodopsin from exiguobacterium sibiricum is a functional proton pump. FEBS Lett. 584, 4193-4196. doi: 10.1016/j.febslet.2010.09.005

Price, M. N., Dehal, P. S., and Arkin, A. P. (2010). FastTree 2 - approximately maximum-likelihood trees for large alignments. PLoS ONE 5:e9490. doi: 10.1371/journal.pone.0009490

Qin, Q.-L., Xie, B.-B., Shu, Y.-L., Rong, J.-C., Zhao, D.-L., Zhang, X.-Y., et al. (2012). Genome sequence of proteorhodopsin-containing sea ice bacterium Glaciecola punicea ACAM 611(T). J. Bacteriol. 194, 3267-3267. doi: $10.1128 / J B .00463-12$

Raymond, J., Siefert, J. L., Staples, C. R., and Blankenship, R. E. (2004). The natural history of nitrogen fixation. Mol. Biol. Evol. 21, 541-554. doi: 10.1093/molbev/msh047

Reinbothe, C., Bakkouri, M., Buhr, F., Muraki, N., Nomata, J., Kurisu, G., et al. (2010). Chlorophyll biosynthesis: spotlight on protochlorophyllide reduction. Trends Plant Sci. 15, 614-624. doi: 10.1016/j.tplants.2010.07.002

Ritchie, A. E., and Johnson, Z. I. (2012). Abundance and genetic diversity of aerobic anoxygenic phototrophic bacteria of coastal regions of the Pacific Ocean. Appl. Environ. Microbiol. 78, 2858-2866. doi: 10.1128/AEM.06268-11

Salka, I., Wurzbacher, C., Garcia, S. L., Labrenz, M., Jürgens, K., and Grossart, H.-P. (2014). Distribution of acI-actinorhodopsin genes in Baltic Sea salinity gradients indicates adaptation of facultative freshwater photoheterotrophs to brackish waters. Environ. Microbiol. 16, 586-597. doi: 10.1111/1462-2920.12185

Schloss, P. D., Westcott, S. L., Ryabin, T., Hall, J. R., Hartmann, M., Hollister, E. B., et al. (2009). Introducing mothur: open-source, platformindependent, community-supported software for describing and comparing microbial communities. Appl. Environ. Microbiol. 75, 7537-7541. doi: 10.1128/AEM.01541-09

Sharma, A. K., Sommerfeld, K., Bullerjahn, G. S., Matteson, A. R., Wilhelm, S. W., Jezbera, J., et al. (2009). Actinorhodopsin genes discovered in diverse freshwater habitats and among cultivated freshwater Actinobacteria. ISME J. 3, 726-737. doi: 10.1038/ismej.2009.13

Sharma, A. K., Zhaxybayeva, O., Papke, R. T., and Doolittle, W. F. (2008). Actinorhodopsins: proteorhodopsin-like gene sequences found predominantly in non-marine environments. Environ. Microbiol. 10, 1039-1056. doi: 10.1111/j.1462-2920.2007.01525.x 
Sievers, F., Wilm, A., Dineen, D., Gibson, T. J., Karplus, K., Li, W., et al. (2011). Fast, scalable generation of high-quality protein multiple sequence alignments using Clustal Omega. Mol. Syst. Biol. 7, 539. doi: 10.1038/msb.2011.75

Tahon, G., Tytgat, B., Stragier, P., and Willems, A. (2016). Analysis of cbbL, nifH, and pufLM in soils from the Sør Rondane Mountains, Antarctica, reveals a large diversity of autotrophic and phototrophic bacteria. Microb. Ecol. 71, 131-149. doi: 10.1007/s00248-015-0704-6

Tamura, K., Stecher, G., Peterson, D., Filipski, A., and Kumar, S. (2013). MEGA6: molecular evolutionary genetics analysis version 6.0. Mol. Biol. Evol. 30, 2725-2729. doi: 10.1093/molbev/mst197

Tytgat, B., Verleyen, E., Obbels, D., Peeters, K., De Wever, A., D'hondt, S., et al. (2014). Bacterial diversity assessment in Antarctic terrestrial and aquatic microbial mats: a comparison between bidirectional pyrosequencing and cultivation. PLoS ONE 9:e97564. doi: 10.1371/journal.pone.0097564

Tytgat, B., Verleyen, E., Sweetlove, M., D’hondt, S., Clercx, P., Van Ranst, E., et al. (2016). Bacterial community composition in relation to bedrock type and macrobiota in soils from the Sør Rondane Mountains, East Antarctica. FEMS Microbiol. Ecol. 92:fiw126. doi: 10.1093/femsec/fiw126

Van Trappen, S., Mergaert, J., and Swings, J. (2004). Loktanella salsilacus gen. nov., sp. nov., Loktanella fryxellensis sp. nov. and Loktanella vestfoldensis sp. nov., new members of the Rhodobacter group, isolated from microbial mats in Antarctic lakes. Int. J. Syst. Evol. Microbiol. 54, 1263-1269. doi: 10.1099/ijs.0.03006-0

Wagner-Döbler, I., and Biebl, H. (2006). Environmental biology of the marine roseobacter lineage. Annu. Rev. Microbiol. 60, 255-280. doi: 10.1146/annurev. micro.60.080805.142115

Wilke, A., Bischof, J., Gerlach, W., Glass, E., Harrison, T., Keegan, K. P., et al. (2016). The MG-RAST metagenomics database and portal in 2015. Nucleic Acids Res. 44, D590-D594. doi: 10.1093/nar/gkv1322

Williams, T. J., Long, E., Evans, F., Demaere, M. Z., Lauro, F. M., Raftery, M. J., et al. (2012). A metaproteomic assessment of winter and summer bacterioplankton from Antarctic Peninsula coastal surface waters. Isme J. 6, 1883-1900. doi: 10.1038/ismej.2012.28

Wurzbacher, C., Salka, I., and Grossart, H. P. (2012). Environmental actinorhodopsin expression revealed by a new in situ filtration and fixation sampler. Environ. Microbiol. Rep. 4, 491-497. doi: 10.1111/j.1758-2229.2012. 00350.x

Yau, S., Lauro, F. M., Williams, T. J., Demaere, M. Z., Brown, M. V., Rich, J., et al. (2013). Metagenomic insights into strategies of carbon conservationand unusual sulfur biogeochemistry in a hypersaline Antarctic lake. Isme J. 7, 1944-1961. doi: 10.1038/ismej.2013.69

Yurkov, V., and Csotonyi, J. T. (2009). "New light on aerobic anoxygenic phototrophs," in The Purple Phototrophic Bacteria, eds C. N. Hunter, F. Daldal, M. C. Thurnauer, and J. T. Beatty (Dordrecht: Springer Netherlands), 31-55.

Yutin, N., Béjà, O., and Suzuki, M. T. (2008). The use of denaturing gradient gel electrophoresis with fully degenerate pufM primers to monitor aerobic anoxygenic phototrophic assemblages. Limnol. Oceanogr. Methods 6, 427-440. doi: 10.4319/lom.2008.6.427

Yutin, N., Suzuki, M. T., and Béjà, O. (2005). Novel primers reveal wider diversity among marine aerobic anoxygenic phototrophs. Appl. Environ. Microbiol. 71, 8958-8962. doi: 10.1128/AEM.71.12.89588962.2005

Zazovskaya, E., Fedorov-Davydov, D., Alekseeva, T., and Dergacheva, M. (2015). "Soils of queen maud land," in The Soils of Antarctica, ed J. G. Bockheim (Basel: Springer International Publishing), 21-44.

Zeng, Y., Feng, F., Medová, H., Dean, J., and Koblížek, M. (2014). Functional type 2 photosynthetic reaction centers found in the rare bacterial phylum Gemmatimonadetes. Proc. Natl. Acad. Sci. U.S.A. 111, 7795-7800. doi: 10.1073/pnas.1400295111

Zhan, A., He, S., Brown, E. A., Chain, F. J. J., Therriault, T. W., Abbott, C. L., et al. (2014). Reproducibility of pyrosequencing data for biodiversity assessment in complex communities. Methods Ecol. Evol. 5, 881-890. doi: 10.1111/2041-210X.12230

Zhan, A., Hulák, M., Sylvester, F., Huang, X., Adebayo, A. A., Abbott, C. L., et al. (2013). High sensitivity of 454 pyrosequencing for detection of rare species in aquatic communities. Methods Ecol. Evol. 4, 558-565. doi: 10.1111/2041-210X.12037

Conflict of Interest Statement: The authors declare that the research was conducted in the absence of any commercial or financial relationships that could be construed as a potential conflict of interest.

Copyright (C) 2016 Tahon, Tytgat and Willems. This is an open-access article distributed under the terms of the Creative Commons Attribution License (CC BY). The use, distribution or reproduction in other forums is permitted, provided the original author(s) or licensor are credited and that the original publication in this journal is cited, in accordance with accepted academic practice. No use, distribution or reproduction is permitted which does not comply with these terms. 